\title{
One Hundred Years of Forgetting: A Quantitative Description of Retention
}

\author{
David C. Rubin \\ Duke University
}

\author{
Amy E. Wenzel \\ University of Iowa
}

\begin{abstract}
A sample of 210 published data sets were assembled that (a) plotted amount remembered versus time, (b) had 5 or more points, and (c) were smooth enough to fit at least 1 of the functions tested with a correlation coefficient of .90 or greater. Each was fit to 105 different 2-parameter functions. The best fits were to the logarithmic function, the power function, the exponential in the square root of time, and the hyperbola in the square root of time. It is difficult to distinguish among these 4 functions with the available data, but the same set of 4 functions fit most data sets, with autobiographical memory being the exception. Theoretical motivations for the best fitting functions are offercd. The methodological problems of evaluating functions and the advantages of searching existing data for regularities before formulating theories are considered.
\end{abstract}

At the simplest level, this article is a search for regularities. We ask whether there is one retention function that can describe all of memory, or perhaps a different function for each of a small number of different kinds of memory. At a more abstract level, it is about the role of theory and data in psychological research. Can we most rapidly advance psychology as a science by developing theories at the level that commonly fills psychological journals such as this one, or should we first try to describe phenomena that could constrain theories by establishing robust, preferably quantitative, regularities (Rubin, 1985, 1989, 1995)? A balance between these alternatives is needed, and here we argue that to obtain such a balance more description is needed.

Retention offers the ideal topic to make this abstract, philo-

David C. Rubin, Department of Experimental Psychology, Duke University; Amy E. Wenzel, Department of Psychology, University of Jowa.

We thank John Anderson, Alan Boneau, John Cerella, Herb Crovitz, Sean Hinton, Armando Machado, Bennet Murdock, Matt Serra, Harold Schiffman, John Staddon, Wayne Wickelgren, and John Wixted for their suggestions; Richard Palmer for information about the exponential-power function and its history and use in physics; Michael Reed for mathematical advice and help with derivations; Robert Terry for statistical advice; and Jenny Zervakis for help with the figures. Support was provided by a Duke University Research Council grant and by National Science Foundation Grant BNS-9010174. Parts of this research were presented in Amy E. Wenzel's senior honor's thesis and at the 35th annual meeting of the Psychonomic Society in St. Louis, MO, in November 1994.

Although we tried to be exhaustive in our search of the literature on retention functions, we must have omitted many relevant data sets. We hope to continue this effort and to maintain as complete a public record of retention functions as is possible. We therefore would be grateful for information about any data sets that we failed to find.

Cor respondence concerning this article, including rcquests for a computer-readable copy of the data sets we have assembled, should be addressed to David C. Rubin, Department of Experimental Psychology, Duke University, Durham, North Carolina 27708-0086. Electronic mail may be sent via Internet to rubin@psych.duke.edu. sophical debate concrete and in doing so to reveal the strengths and weaknesses of the different approaches. At the theorydriven extreme are proponents who derive retention functions from first principles: either differential equations describing memory mechanisms (Wickelgren, 1972, 1974a, 1974b) or more global principles of optimization (Anderson, 1990; Anderson \& Schooler, 1991). At the data-driven extreme is the present attempt to search the literature for as many data sets as possible and to fit each one with as many functions as can be practically managed in order to provide the most theory-neutral empirical description possible.

How should we do science efficiently? When is it most efficient to speculate, when is it most efficient to produce a formal mathematical model, and when is it most efficient to search the data and describe regularities? In high school science and in graduate school experimental design, we are taught to first formulate a theory, to next derive testable hypotheses, and finally to test them experimentally. We usually write our papers (and always write our grant proposals) as if we did only this. But many advances in science have been made by documenting and accumulating regularities, often quantitative regularities, and only then developing theories to account for them. Theories so developed are next tested on novel predictions and altered or abandoned as needed. In psychology the latter approach is most often seen in contemporary mathematical modeling; it is the one favored here. However, in many areas, such as retention, we are at the stage where the lack of a documented regularity makes theory formulation inefficient and the phenomenon itself is ignored in theory building (Brainerd, Reyna, Howe, \& Kingma, 1990; Ratcliff, 1990; Slamecka \& McElree, 1983). For these cases, quantitative descriptions in a form that is as theoryneutral as possible are needed before theory can be efficiently developed. The data for such a description have been accumulating for over 100 years.

Among the basic inquiries Ebbinghaus (1885/1964) made when he began the experimental study of human memory was an investigation of the shape of the retention function. He learned lists of nonsense syllables until he could recite them 
twice perfectly and then measured the percentage of time saved when he tried to relearn them later at delays ranging from 20 min to a month. His data provide the classic retention function: smooth, monotonic, decreasing rapidly at first, but then leveling. Ebbinghaus proposed the function $y=100 \cdot a /\left\{[\log (t)]^{b}\right.$ $+a\}$ to fit his data but mentions no other functions he considered. The search has continued in much the same fashion for the last century, with each researcher considering at most a handful of data sets and functions.

Here we make an evaluation that is as unbiased as possible of what we now know. Our work builds on studies testing one or two theoretically motivated functions on a variety of data sets (e.g., Indow, 1993; Laming, 1992; Wickelgren, 1972, 1974a; Woodworth, 1938) and on studies comparing a handful of functions using one (Rubin, 1982) or a handful (Anderson \& Schooler, 1991; Wixted \& Ebbesen, 1991) of experimental procedures. We differ from these earlier careful and informative studies mainly in our lack of selectivity of functions and data sets. Unlike most previous attempts, no new data are collected; we find it inefficient to add to a large database before evaluating it to find what data are needed. Unlike most previous attempts, no single function is favored on theoretical grounds; the more standard scientific approach for our level of knowledge is first to determine which functions fit the data and only then attempt to account for these findings theoretically. That is, we initially view retention as an empirical observation rather than as an hypothesized process, reserving theory building until the retention function is described in relatively neutral terms (Slamecka, 1985). Theory is not abandoned; we know a great deal about retention that is needed for an intelligent investigation. However, theory must fit the existing data, and for retention there is considerable existing data.

\section{An Outline}

First, we review some fundamental questions that have been raised in the long history of the study of retention functions. We do this to guide our analysis of the existing data, to develop a set of questions we will ask of the data, and to benefit from insights gained in earlier work.

Second, we describe 210 data sets from the psychological literature that (a) have a measure of amount remembered as one variable and time since learning as a second variable, (b) have 5 or more points, and (c) fit at least one of the two-parameter functions tested with a correlation of .90 or greater. The first criterion is the definition of a retention function. The second criterion ensures enough points to differentiate among two-parameter functions. A straight line can fit any two points perfectly. A smooth curved line can usually fit three points perfectly if the points are monotonically decreasing and one selects from as many functions as are used here. We therefore required two data points beyond this minimum. The third criterion limits our database to smooth plots. Thus we use arbitrary but reasonable, objective, and easy-to-apply criteria to assemble as large and unbiased a collection of data sets as possible.

Third, we describe the set of 105 two-parameter functions to which we fit each of the 210 data sets. We include the standard linear, hyperbolic, logarithmic, exponential, and power functions. We also include some novel ones. However, they are no stranger than Ebbinghaus' (1885/1964) original attempt, or $\ln (y)=\ln (a / 2.51)-\left(a^{2} / 2\right) \cdot(\ln (t)-b)^{2}$, which was among those considered by Rubin (1982). At this stage no attempt is made to limit our search to theoretically motivated functions. If a function fits, the challenge we face is to explore its properties or to derive it from reasonable principles. Thus even a function as odd as the one just given is a form of the lognormal distribution, and it would have theoretical interest if it fit the data.

Fourth, we sort this mass of over 22,000 correlations for patterns. In particular we expect to find that one of the following three patterns will hold. First, one function (or a small set of equally good-fitting functions) fits all the retention data; that is, within experimental error there is one retention function that describes all procedures and participants tested. Second, different functions (or different sets of functions) fit different classes of data sets; for instance, there may be one function for recall data and another for recognition data. Third, no patterns emerge; that is, there is no lawful way to generalize over data sets to provide a quantitative description of retention. The search for one of these three patterns must be done before any serious theoretical work. Psychologists have assumed that the first or second option would hold, but this is an empirical question. Because many arbitrary decisions are made in such a descriptive undertaking and because inferential statistics to check such decisions are not always possible, we make our collection of data sets available to others so they may try their own procedures.

Fifth, we review the results in terms of the questions raised by the initial literature search and in terms of new practical and theoretical questions that arise. We include theoretical derivations for the best fitting functions, and we suggest useful studies that we did not find in the literature. Finally, we examine the implications of the research approach undertaken and ponder how psychology can most rapidly advance as a science.

Two notes of caution should be introduced before proceeding. The first is that although the study of retention functions is often called the study of forgetting, what is remembered is measured, not what is forgotten. Items not remembered can be assumed to be forgotten only on the one instance in which the measurement was made. They may be remembered in a different but otherwise similar situation or under different testing conditions. The second caution is that time is the independent variable in all studies reported here, but time is not what is important to retention. How the time is filled is what matters (Baddeley, 1990; McGeogh, 1932; Rubin, 1995). Time is the best index we have of the amount of interfering or competing activity that has occurred in the retention interval. In singlesession studies the activity that fills the retention interval is known. In multiple-session studies it is assumed to be equal during the various intervals.

\section{An Example}

Before presenting a literature review and an analysis of actual data sets, idealized data sets are used to provide a graphic indication of both the functions to be considered and of the goodness of fit of various degrees of $r^{2}$. To accomplish this, two data sets were formed that were generally smooth and monotonically decreasing. The goal was not to produce the most scientifically 
informative data sets, but realistic ones in which a lack of fit could be attributed mostly to the shape of the function rather than to noise in the data. Data from classic studies in the shortterm memory for material learned in the laboratory were averaged, as were data from a classic study of very long-term memory for material learned outside the laboratory.

The first data set is an average of the short-term memory study of Peterson and Peterson (1959) with a replication by Murdock (1961) for the conditions in which he used trigrams and word triads (Experiment 1, Sessions 1 and 3 ). In these experiments participants were presented with three letters or words, counted backward during the retention interval that lasted as long as $18 \mathrm{~s}$, and then recalled the three items. Murdock replaced Peterson and Peterson's 15-s retention interval with an immediate retention interval, and we used Murdock's intervals in combining data sets.

Murdock (1961) reported his immediate retention interval as $0 \mathrm{~s}$. When time is computed or plotted on a linear scale, as Murdock did, zero is a good estimate of "immediate," but when logarithmic scales are also used, zero is undefined. In experiments, immediate recall is never at zero but is after the participant is signaled to recall, or turns the page, or looks down to begin writing, or according to Murdock's description, after a metronome set to $1 \mathrm{~s}$ has sounded. From Murdock's description of his procedure, we assumed that the total time for his immediate retention interval actually occurred $1 \mathrm{~s}$ after learning. Our results would change only slightly if $.1 \mathrm{~s}$ or $.5 \mathrm{~s}$ were chosen instead of $1 \mathrm{~s}$, but the alternative of omitting the immediate recall interval results in larger changes and more data loss. Similar assumptions were made for all data sets in this article reporting a zero retention interval, and our assumed values are listed in Tables 1 to 9 . As the data sets are in the public domain, alternatives can be freely considered.

The second data set was made by combining all six free recall measures from Bahrick's (1983) long-term memory study of recall of campus locations. As with the Murdock (1961) study, a time had to be assumed for a retention interval for immediate recall. From Bahrick's procedures we decided that the undergraduates probably saw the average city or campus location about 3 days (.008 years) before their "immediate" test. The $100 \%$ value at "immediate" is not a ceiling effect but the result of Bahrick normalizing his data by dividing recall at all retention intervals by that at the "immediate" one.

Figure 1 presents the two data sets fit to four of the most commonly used retention functions. The most striking feature is the similarity of the appearance of the plots, given that one covers an 18-s range and the other a 46-year range. For the short-term memory data set, the exponential function fits well, as claimed in the original articles. But all functions presented fit well, with the power function providing a slightly poorer fit than the others. For the long-term memory data set, it is easier to distinguish among the functions, with the logarithmic function fitting best (as it technically does in the short-term data set) followed by the power, hyperbolic, and exponential functions, a pattern we will see again. Both the power and the logarithmic function rise rapidly to infinity as the retention interval shrinks to zero, and so for the long-term memory data set, both can more easily fit the "immediate" data point. A linear function, $y=b-m t$, does not fit the short-term and long-term memory data sets as

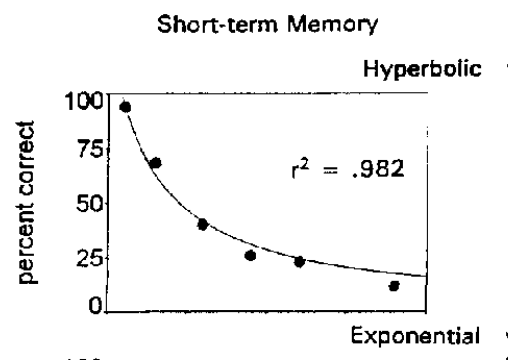

Long-term Memory
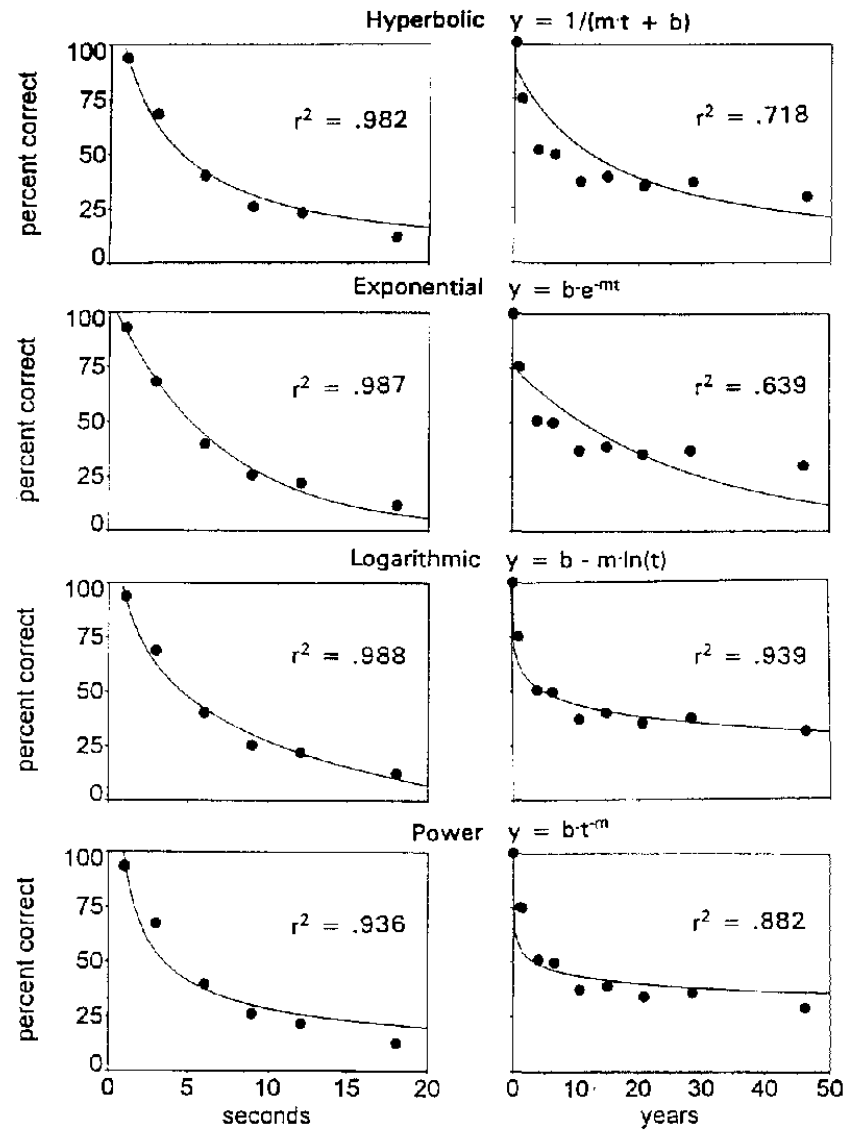

Figure 1. Retention data for an idealized short-term and an idealized very-long-term memory experiment fit to four common functions. For this figure and throughout the article, $y$ is always a measure of remembering, $l$ is time from learning, and $m$ and $b$ are positive, empirically fit constants.

well as the functions shown with $r^{2}$ s of .821 and .486 , respectively.

Unlike previous studies comparing retention functions (e.g., Anderson \& Schooler, 1991; Rubin, 1982; Wixted \& Ebbesen, 1991 ), the fits presented were made to the untransformed data as shown in Figure 1 rather than to transformed data. It could be argued that there is some theoretical (Estes, 1956) or practical (Newell \& Rosenbloom, 1981) reason to transform the data or not to (Slamecka \& McElree, 1983), but transformations do not make for a fair comparison among different functions. The logarithmic function would not change, but the hyperbolic function would be fit as $1 / y=b+m \cdot t$, the exponential as $\ln (y)$ $=b-m \cdot t$, and the power as $\ln (y)=b-m \cdot \ln (t)$. The parameters of the fits and the $r^{2}$ values differ in the two methods. For the method used here $(y-\hat{y})^{2}$ is always minimized, where the

indicates the estimate based on the best fitting parameters for the function. For the approach used in the earlier literature, $(y$ $-\hat{y})^{2}$ is used for the linear and logarithmic functions, $(1 / y-$ $1 / \hat{y})^{2}$ for the hyperbolic, and $[\ln (y)-\ln (\hat{y})]^{2}$ for the exponential and power. The $r^{2}$ values change because they are defined as one minus these values divided by the variance in $y$, or $1 / y$, and 
$\ln (y)$, respectively. The rank orderings of the $r^{2} s$ of the fits for the four functions in Figure 1 do not change for the two data sets when the transformed functions are fit, but the values do. For the short-term memory data sets, the hyperbolic, exponential, and power fit the transformed data with $r^{2}$ s of $.973, .969$, and .932 . For the long-term memory data sets, the $r^{2} s$ are .736 , .612 , and .881 , respectively. Thus, in the transformed data, the fits are slightly more differentiated.

\section{Some Fundamental Questions About Retention Functions}

Many of the questions about the shape of retention functions that have been considered in the literature can be divided into three classes. The first and most theoretically contentious class of questions concerns how retention functions should be measured, considered, and compared. The second class of questions concerns whether there is one retention function for all of memory or whether there are different functions for (a) different degrees of learning and overlearning, (b) short and long intervals, (c) different participant populations, (d) different materials or different learning processes, and (e) different memory tasks. The third class concerns dependent measures.

\section{How Should Retention Be Measured?}

Among the first class of questions, several approaches are possible, and there is no simple consensus. Bahrick (1965) has noted advantages for plotting functions in units of variance, Slamecka and McElree (1983) have argued for a standard analysis of variance (ANOVA) technique, Loftus (1985a, 1985b; Loftus \& Bamber, 1990) has developed a theoretical framework based on comparing functions horizontally instead of vertically, and Bogartz (1990a, 1990b) has considered splitting the observed function into underlying unobserved components corresponding to assumed memory processes. The simplest approach, and the one adopted here, is to fit the empirical data using standard curve-fitting techniques first and to consider complications only if necessary.

There are two reasons to opt for the simplest approach first. The obvious one is that, until the collection of data sets is considered, it is not clear that the added complexity will aid our understanding of the data. If the best fitting function does not require the $y$ axis to be transformed, the same conclusions will be drawn under both the ANOVA and curve-fitting approaches, and thus Slamecka and McElree's ( 1983) arguments would be less relevant $(x$-axis transformations are irrelevant because time values never enter into Slamecka and McElree's ANOVAs). Loftus's horizontal difference proposal has advantages, but these appear naturally only if the retention function is an exponential, which may or may not occur. Similarly, we may need to divide our function into one component for initial learning and one for retention (Bogartz, 1990b, Rubin, 1985), into one component that reflects the nature of the retrieval task and one for retention, or in any of a host of other ways depending on the differences observed across conditions. Thus, it is most efficient to wait until the results are examined to make such decisions.

The second reason for choosing the simplest empirical curvefitting approach is more subtle and concerns the nature of the available data. Empirical retention plots are usually aggregates over both many items and many participants. Ebbinghaus (1885/1964), Jans and Catania (1980), Nelson and Wasserman (1978), Rubin (1982, 1989), White and McKenzie (1982), and Wickelgren (1968) are some exceptions that do not group over both dimensions simultaneously. However, because in most procedures the same item cannot be tested repeatedly with the same participant without providing additional retrieval practice, grouping over either participants or items is necessary for most questions of interest. Moreover, in many procedures, such as those involving learning to a criterion or all of Bahrick's very-long-term studies, there are multiple exposures to the material to be tested. Thus, an implicit average over time is used, with the last time that material was presented in an assumed learning period taken as the beginning of the retention interval.

Mechanistic models predict what individual participants do on individual trials (e.g., Staddon, 1993). The difference between such models and the heavily aggregated data at hand can be large. Data are lost that would allow the model to separately consider the time course of each presentation of a multiply presented item or differences among individual items or participants. In the extreme case, a set of all-or-none step functions for individual items or participants could be summed to form any of the aggregate functions considered here (for a review, see Kausler, 1974, pp. 8-10, 153-158). Even if all individual participants (or items) were described by the same function but with different parameters, for some functions the resulting aggregated function would not be the same one as the individual participants' (Estes, 1956). Therefore, it seems more reasonable initially to be satisfied with an empirical description that could constrain theorizing of all kinds than to embark on a search for a more complex theoretical framework that involves assumptions that would not apply to all models.

\section{Is There One Retention Function for All Conditions?}

There is little reason to assume that retention functions will differ or not differ along any particular dimension until existing data and theory are examined. The approach used here is to group the data sets along different dimensions guided by what we already know about memory and to see if any groupings produce functions that are more similar within the groups than between them. The basic questions are whether there is one retention function or many, and if there are many, what characterizes the different kinds (Luh, 1922). If retention is viewed as an observable, empirical phenomenon as opposed to an inferred mental process (Bogartz, 1990a), then the answer to this question depends on the function that is chosen as the best empirical description. Different choices of a function could lead to different conclusions for the same data. Nonetheless, in most of the debate so far, regardless of theoretical positions on how retention should be measured, the equation has either been assumed to be $y=b \cdot e^{-m t}$ or has been chosen to fit the particular data set (Bogartz, 1990a, 1990b; Loftus, 1985a, 1985b; Loftus $\&$ Bamber, 1990). If a retention function (or a set of retention functions) could be chosen that fit a class of retention data, one could return to this question using that function.

The particular question that has generated the most debate in 
recent years is whether retention functions differ with the amount of learning (Bogartz, 1990a, 1990b; Loftus, 1985a, 1985b; Loftus \& Bamber, 1990; Slamecka, 1985; Slamecka \& McElree, 1983; Wixted, 1990). Slamecka and McElree (1983) examined the literature on the effects of degree of learning on retention and found that

A fair summary of the appearance of forgetting curves from all sources reviewed is that they either had equal slopes or slopes that varied directly with intercept levels. There were no slopes that varied inversely with intercepts, meaning no cases where forgetting was less at higher degrees of learning. Further where slopes varied directly with intercepts, floor effects clouded the picture. This leaves only the finding of equal slopes. (pp. 386-387)

Anderson and Schooler (1991), reanalyzing data from Hellyer (1962) and Krueger (1929), arrived at a similar conclusion. Rubin (1985) extended this finding to memory for prose. The rank order of the units of text from most to least likely to be recalled was constant over a range of times from immediate to 3-month recall. Thus, for items within the same passage, retention functions for different levels of initial learning do not cross.

A second dimension is whether the retention function used to describe forgetting over intervals of up to $30 \mathrm{~s}$ is the same as the retention function for longer intervals. What is at stake here is whether short-term and long-term memory function the same or differently (Wickelgren, 1973). Researchers have taken positions on this issue, arguing for the same (Wickelgren, 1974a) or for different (Wickelgren, 1974b) functions. With the switch from a 30-s duration short-term memory to a 2-s duration articulatory loop for working memory (Baddeley, 1986), much of the theoretical impetus for this debate has dissipated, but the empirical question remains as to whether the same or different functions best fit retention at different intervals. A second motivation for considering different time intervals comes from Bahrick's (1984) work on permastore, the claim that forgetting of certain domains virtually stops after a few years. Here the contrast is not between time intervals less than and longer than $30 \mathrm{~s}$ but between intervals less than and longer than a few years.

A third dimension is whether aspects of the population tested affect the shape of the retention function, with age being the factor most often considered. Most researchers report no age difference (Fajnsztejn-Pollack, 1973; Hulicka \& Weiss, 1965; Morrison, Haith, \& Kagan, 1980; Rubin, Wetzler, \& Nebes, 1986; Wickelgren, 1975a) or at most small differences (Giambra \& Arenberg, 1993). The major effort to counter to this general finding comes from Brainerd et al. (1990). To find an exception, which was their stated goal (pp. 74-75), they claimed one needs to fulfill five conditions: recall tests, less memorable material, long retention intervals, learning to a criterion of one or more errorless recalls of all items in a list, and a Markov model to equate the degree of initial learning and measurc retention. The first three conditions limit the generality of the exception. The condition of learning a whole list to criterion, which was initially used by Ebbinghaus (1885/1964), causes known problems in that the more trials a participant needs to reach criterion, the more overlearned are the first learned items on the list (Guttentag, 1990; Rubin, 1995). Because children will take longer than adults to learn a list, this causes a differential effect with age. The fifth condition of a Mar- kov model is claimed to overcome this problem, but it requires the use of a particular model to equate learning, and thus the counterevidence depends entirely on the validity of the model. Given these restrictions, the conservative conclusion to the existing data is that retention, as opposed to initial learning, is not affected by age over the range of ages tested or is at most affected under only specific conditions and assumptions.

Similar effects occur with changes other than age. Wickelgren (1975b) found that mildly intoxicated students had decrements in memory performance compared with those who were sober, but they showed no change in the retention function or the rateof-forgetting parameter. Wickelgren even noted that the amnesic, H.M., had retention functions and slopes that were in the normal range for times of up to $16 \mathrm{~s}$ in one study (Wickelgren, 1968 ) and up to $12 \mathrm{~min}$ in another (Wickelgren, 1974a), although H.M.'s data are noisy enough to hide a fairly large difference.

A fourth dimension is the effect of changes in the material learned and the learning process on the shape of the retention function. Limited evidence again supports a simple outcome. In reviewing the literature, Underwood (1966) found that once lists are learned to the same level, the course of later retention is not dependent on any other independent variable measured. Similarly, Nelson and Vining (1978) showed that retention was not affected by changing an orienting task from semantic to structural as long as the level of initial learning was the same. Although these findings say nothing about the shape of the retention function, they imply that whatever the shape, it will be constant in terms of both the function and its parameters over a host of variables if the degree of initial learning is the same.

The fifth dimension is whether different test procedures used to measure retention require different functions. The early experimental psychologists most thoroughly investigated this question. When Burtt and Dobell (1925) compared recall and recognition of advertising material, they determined that recognition yielded greater absolute values but that the two functions approximated each other. Luh (1922) had participants learn lists of words to compare the methods of anticipation, relearning, written reproduction (i.e., recall), recognition, and reconstruction of the serial order given the items. Relearning, measured in percent savings, fell much less rapidly at longer time intervals than the other measures, resulting in a differently shaped plot. Tsai (1924) determined that savings measured in terms of time, trials to criterion, or number of errors were similar, being affected only by the value of the initial amount remembered. In summary, different measures of relearning produce the same retention function, but this function is different from that produced by recall. All other standard testing procedures, however, appear to yield plots with the same shape as that of recall.

\section{What Dependent Measure Is Best?}

It is possible to use different dependent measures with the same testing procedures. Converting all data sets to many possible dependent measures to allow a full study of this issue would be useful, but it is beyond the scope of this article. However, eventually some transformation of either the data or the theoretical predictions will be needed. In particular, the most 
common dependent measure reported, percentage correct, cannot be a measure of underlying memory strength in most models. At a minimum it fails to distinguish degrees of overlearning at $100 \%$ correct and degrees of what might be left at $0 \%$.

The second most common measure after percentage correct is $d^{\prime}$, which is used to report many studies of recognition memory. $d^{\prime}$ is a measure of sensitivity from statistical decision theory (Green \& Swets, 1966). It is analogous to a $t$ test in that its numerator is the difference of the means of two distributions and the denominator is a measure of the standard deviation of the distributions. The data used to estimate the means of the distributions are the probabilities of saying that a word that occurred earlier in an experiment when it did occur (i.e., the probability of a hit ), $p$ (hit), and the probability of saying that a word that occurred earlier in an experiment when it did not (i.e., the probability of a false alarm), $p(\mathrm{fa})$. Two methods are used in memory experiments to transform the $p$ (hit) and $p$ (fa) measures to a scale with a unit standard deviation so that they can be subtracted to yield $d$. In the simplest method, $p=.5$, which is the location of the mean of the underlying distribution, is subtracted from both $p$ (hit) and $p(\mathrm{fa})$. These values are converted to normal deviate scores, or $z$ scores- $z$ (hit) and $z$ (fa) - and subtracted from each other to produce $d^{\prime}$. In the more complex method, memory operating characteristic curves are formed by obtaining not only yes-no decisions for each word presented for recognition but also confidence ratings. $A p($ hit $)$ and $p(f a)$ for each level of confidence is plotted on double-probability paper with normal deviate scales, and $d^{\prime}$ is determined graphically (see Wickelgren, 1972, for more details).

In some memory experiments, such as those using continuous recognition, the false-alarm rates are for items not seen before, and thus they have no retention interval. Researchers using $d^{\prime}$ for such experiments therefore assume that the false-alarm rate does not change with retention interval; that is, for example, that participants do not relax their criterion when they think that an item occurred a long time ago. Thus the level of $p$ (fa) used is the same for all retention intervals, and changes in $d^{\prime}$ must be due to changes in $p$ (hit) or in the simpler method described, $z$ (hit). If the transformation from $p$ (hit) to $z$ (hit) were linear, then $d^{\prime}$ would be a linear transformation of percentage correct. Over the range of $p$ (hit) $=15 \%$ to $85 \%$, this is a fair approximation. In fact, Wixted and Ebbesen (1991), whose recognition-experiment points all fell in this range, found that percentage correct and $d^{\prime}$ yielded the same functions. At more extreme values, small changes in proportion correct yield large changes in $z$ scores and thus in $d^{\prime}$. Thus, one might expect plots fit to $d^{\prime}$ and proportion correct to differ most for $y$ values near $0 \%$ and $100 \%$.

Another common dependent measure is $\log d$, which is used in studies of animal discrimination. $\log d$ is the $\log [p$ (correct) $/ p$ (wrong) $]$ averaged over the two stimuli of the discrimination experiment. If the animal makes a choice on each trial, it becomes $\log [p($ correct $) /(1-p$ (correct) $)]$, which is the same as the log of the odds measure introduced independently into the literature by Anderson and Schooler (1991). The measure has useful properties for animal research and also can be seen as a variant of $d^{\prime}$ (White, 1985; White \& McKenzie, 1982). The studies using laboratory animals as subjects tend to report their data in detail, and we can therefore report analyses based on proportion correct to allow a comparison with other studies.

Anderson and Schooler (1991) have used an odds measure equal to $p /(1-p)$ with empirical success. Their measure has advantages in terms of their theory and lets the dependent measure go to infinity as $t$ approaches zero as needed by the twoparameter logarithmic and power functions.

Bahrick ( 1965 ) proposed the ebb as a unit based on percentage correct. His argument was as follows. Recall or recognition data yield a dichotomy of remembered or not remembered. The proportion remembered represents the proportion of memories that have a strength above a threshold. The observed retention function for percentage or proportion correct depends not only on how these unobserved, inferred strengths weaken with time, but also on the shape and variance of their distribution and the position of the threshold relative to the distribution at $t=0$. Without added assumptions, the added factors about the underlying strength cannot be known. If the weak assumption is made that the distribution is normal, then normal deviate scores can be used to assess the position of the mean strength from the proportion correct scores, as is done in estimating $d^{\prime}$. In fact, the ebb measure can be seen as the half of the $d^{\prime}$ measure based on hits. Because of the shape of the normal distribution, the ebb measure provides a transformation that separates percentage correct scores near 0 and $100 \%$ much more than scores near 50\%. Bahrick's ebb measure was not adopted here because of the desire to first describe the data with as few assumptions or transformations as possible, but like $d^{\prime}, \log d$, and the odds ratio, it is a reasonable first step in going from the observed data to the realm of underlying process needed to evaluate proposed theoretical mechanisms.

The $d^{\prime}$, ebbs, and odds ratio can have serious measurement problems for most psychological data. In retention experiments, changes of .01 in probability are hardly ever reliable. That is, an observed proportion correct of .99 will result in a value of .98 or 1.00 on replication, with a probability not much lower than that of obtaining the original value of .99. Yet the odds measure can vary dramatically with .01 changes that occur near $p=1.00$. The odds for $p=.50, .51, .52$, and .53 go from 1.00 to 1.04 to 1.08 to 1.13 in small, nearly uniform steps so that a random change among them on replication would not greatly alter a curve fit. In contrast, the odds for $p=.97, .98$, .99 , and 1.00 go from 32 to 49 to 99 to infinity. The nonlinearity is less important in the $\log d$ measure used with delayed matching to sample in animals (e.g., White, 1985), because in these studies individuals and groups rarely approach extreme levels of performance. But where the probability of retention approaches 1.00 ( or 0.00 for $d^{\prime}$ and the log odds ratio), care must be taken to ensure that the confidence intervals around the points are reasonable for the transformed values. If this is not possible, the empirical values can be left as percentage correct, and the theoretical values in terms of $d^{\prime}$ odds, or ebbs can be transformed into percentage correct values.

Other dependent measures, including savings (Ebbinghaus, 1885/1964; Finkenbinder, 1913; see Bahrick, 1965, for a discussion) and discrimination index (Nelson \& Wasserman, 1978), are each used in one or more studies but, except for savings, do not provide enough data for comparisons. 
In summary, the studies to date indicate that aspects of the participant population and materials have little effect on the shape of the retention function if the level of initial learning is controlled. The testing procedures used do have an influence but, except for the savings, these appear to be relatively minor in practice. If this conclusion holds on closer investigation and if it applies to other factors, a relatively simple empirical description may be available in which the same function (or set of functions) with the same parameters holds over a range of conditions once the level of initial learning is controlled. Transformations of the data from percentage correct to $d^{\prime}$, ebbs, log $d$, or odds ratio affect curve fitting to various degrees, but these mathematical transformations should be viewed separately from the procedures used to produce the data. Moreover, the relation of any of these observed measurements and underlying memory strength cannot be decided outside the context of a theory. With full reporting of the data, they can be applied at will depending on the psychometric properties of the data and the theoretical disposition of the researcher.

\section{The Data Sets}

\section{General Criteria and Procedures}

The literature was searched to assemble a sample of data sets ${ }^{1}$ that each had five or more data points consisting of a measure of the amount remembered as one value and the time since learning as a second value and that fit at lcast one of the twoparameter functions tested with a correlation of .90 or greater. These data sets are organized in Tables 1 to 9 according to major divisions that might cause differences in their retention functions. Other important features of the data sets are listed along with identifying information so that the reader can entertain some alternative hypotheses from the tables and can formulate others by examining the full description of the studies in their original publications. Data sets in Tables $1-9$ are labeled with the number of the figure or table in the original article from which the data were extracted. If more than one data set was taken from the figure or table, then we added a one- or two-letter code to distinguish between the specific data sets. Some of these codes may seem opaque here but are easier to interpret in the context of the original articles. In a few cases two data sets represented the same conditions but were tested in terms of two different tasks (e.g., Bahrick, 1984, Figure 6). In this case, the labels are identical, and the data sets can be distinguished by the task column.

We did not convert the data sets to common units. The exceptions are that all values for percentage correct, proportion correct, and number correct are reported as percentage correct. The units of time are those reported in the original studies. We kept the original units to allow the reader to more easily match and compare our description of the data with that in the original articles, to avoid the awkwardness of having to report values that are difficult to understand, such as $1.46 \times 10^{9} \mathrm{~s}$ for the 46.33-year retention interval of Bahrick (1983), and because the unit change does not affect the $r^{2}$ values reported.

There are two exceptions to our attempt to be as inclusive as possible. First, we did not search for data sets that had a longest retention interval of shorter than a few seconds. Second, we did not include studies that explicitly studied reminiscence because such studies often use repeated testing of participants and score performance differently from most retention studies (see Roediger \& Payne, 1982, and Wheeler \& Roediger, 1992, for reviews). For example, Ballard (1913) obtained reminiscence in part because, for each retention interval, he counted answers correct if students answered them correctly in that or in previous retention intervals.

\section{Data Sets From the Laboratories of Bahrick and Wickelgren}

Two laboratories were responsible for many of the data sets. We list these separately to assess how much variability can be expected among studies performed in the same manner. The variability within each laboratory provides a baseline against which differences among laboratories and techniques can be compared. For these purposes it is fortunate that the two laboratories differ so greatly in their methods. We cannot do justice to the amount of effort and importance of the work done in these two laboratories, or in the studies from other laboratories that enter as a line or two in a table here. Rather we provide just enough information to allow interpretation of the results and to provide concrete examples of the kind of studies involved.

The research from Bahrick's laboratory reported here in Table 1 is mostly of material learned outside the laboratory while participants were growing up in the United States and then later tested, usually under controlled conditions. A range of materials has been used, including the names and faces of high school classmates, information about the layout of the city in which college was attended, and Spanish learned in school. Dependent measures varied as needed to test the material and included free and cued recall, recognition, matching names and locations or names and faces, and Spanish reading comprehension. As with many laboratory studies, different participants were tested at each retention interval, but here the participants were not randomly assigned. To produce a large range of retention intervals, typically from 3 months to 50 years, the age of the participant at the time of testing and retention interval were confounded. For instance, all participants learned the names of their high school classmates in high school. Therefore participants tested at the longer retention intervals were older than those tested at the shorter retention intervals. In many laboratory studies of retention, the material is presented once in the laboratory and tested once in the laboratory, either for its contents or for the fact that it occurred within the laboratory session. In contrast, in the Bahrick studies the material was presented and tested many times in the course of life outside the laboratory and then tested once in a laboratery-like situation.

The research from Wickelgren's laboratory reported in Table 2 provides a contrast in that it uses a procedure and dependent measure Bahrick did not use, usually uses the same participants at all time intervals, and has its longest retention intervals shorter than most of Bahrick's shortest retention intervals. In a typical study, participants were presented with a series of words,

\footnotetext{
${ }^{1} A$ computer-readable copy of the data sets is available from David C. Rubin.
} 
Table 1

Descriptions of Data Sets From Bahrick's Laboratory With Fits to Selected Functions

\begin{tabular}{|c|c|c|c|c|c|c|c|c|c|c|c|}
\hline \multirow[b]{2}{*}{ Study ${ }^{\mathbf{a}}$} & \multirow[b]{2}{*}{ Task } & \multicolumn{2}{|c|}{ Range } & \multicolumn{8}{|c|}{$r^{2}$ fit of selected functions } \\
\hline & & Time & $\%$ correct & Lin & Hyp & $\operatorname{Exp}$ & $\log (m)$ & Pwr & EP & HP & $\mathrm{Hi}$ \\
\hline \multicolumn{12}{|c|}{ Bahrick et al. (1975) } \\
\hline 4 & $\mathrm{FR}$ & $3 \mathrm{mo}-48 \mathrm{y}$ & $47-20$ & .90 & .87 & .89 & $.73(3.9)$ & .69 & .83 & .80 & .90 \\
\hline $4 \pi$ & MG & $3 \mathrm{mo}-48 \mathrm{y}$ & $90-59$ & .89 & .85 & .87 & $.55(4.7)$ & .52 & .75 & .72 & .94 \\
\hline \multicolumn{12}{|l|}{ Bahrick (1983) } \\
\hline 8 & FR & $3 d-46 y$ & $100-31$ & .20 & .73 & .43 & $.86(9.3)$ & .84 & .74 & .88 & .98 \\
\hline 8 & MG & $3 \mathrm{~d}-46 \mathrm{y}$ & $100-23$ & .41 & .92 & .76 & $.92(10)$ & .85 & .93 & .95 & .95 \\
\hline 8 & CR & $3 d-46 y$ & $100-7$ & .33 & .96 & .88 & $.94(11)$ & .91 & .95 & .95 & .98 \\
\hline $9 \mathrm{ca}$ & FR & $3 d-46 y$ & $100-39$ & 67 & .88 & .78 & $.85(7.2)$ & .78 & .96 & .97 & .97 \\
\hline $9 \mathrm{ca}$ & $\mathrm{CR}$ & $3 d-46 y$ & $100-28$ & .57 & .92 & .78 & $.88(9.1)$ & .79 & .95 & .96 & .96 \\
\hline $9 \mathrm{ci}$ & $\mathrm{CR}$ & $3 d-46 y$ & $100-1$ & .53 & .92 & .80 & $.91(11)$ & .82 & .93 & .92 & .93 \\
\hline $9 \mathrm{ci}$ & FR & $3 d-46 y$ & $100-16$ & .69 & .97 & .88 & $.82(9.6)$ & .71 & .97 & .92 & .97 \\
\hline $9 \mathrm{ci}$ & MG & $3 \mathrm{~d}-46 \mathrm{y}$ & $100-45$ & .56 & .80 & .68 & $.73(7.1)$ & .66 & .86 & .88 & .87 \\
\hline $9 \mathrm{ca}$ & MG & $3 d-46 y$ & $100-59$ & .79 & .88 & .84 & $.73(4.5)$ & .68 & .95 & .95 & .95 \\
\hline $10 \mathrm{~s}$ & FR & $3 d-46 y$ & $100-15$ & .16 & .93 & .95 & $.83(12)$ & .85 & .92 & .88 & .95 \\
\hline $10 \mathrm{~s}$ & CR & $3 \mathrm{~d}-46 \mathrm{y}$ & $100-20$ & .22 & .84 & .69 & $.89(10)$ & .92 & .84 & .92 & .92 \\
\hline $10 \mathrm{i}$ & FR & $3 d-46 y$ & $100-35$ & .59 & .78 & .69 & $.87(7.3)$ & .82 & .88 & .91 & .91 \\
\hline $10 \mathrm{l}$ & CR & $3 \mathrm{~d}-46 \mathrm{y}$ & $100-36$ & .47 & .73 & .58 & $.85(7.7)$ & .80 & .84 & .90 & .90 \\
\hline $10 a$ & FR & $3 d-46 y$ & $100-43$ & .79 & .88 & .84 & $.80(5.9)$ & .74 & .95 & .94 & .95 \\
\hline \multicolumn{12}{|l|}{ Bahrick (1984) } \\
\hline $6 s v$ & CR & $.1 \mathrm{mo}-50 \mathrm{y}$ & $57-22$ & .39 & .53 & .45 & $.90(1.3)$ & .88 & .72 & .83 & .93 \\
\hline $6 s v$ & RG & $.1 \mathrm{mo}-50 \mathrm{y}$ & $62-45$ & .19 & .21 & .20 & $.75(.32)$ & .77 & .40 & .44 & .87 \\
\hline $6 \mathrm{ev}$ & $\mathrm{CR}$ & $.1 \mathrm{mo}-50 \mathrm{y}$ & $66-21$ & .33 & .56 & .41 & $.89(1.6)$ & .88 & .72 & .86 & .97 \\
\hline $6 \mathrm{ev}$ & RG & $.1 \mathrm{mo}-50 \mathrm{y}$ & $69-47$ & .36 & .40 & .38 & $.80(.39)$ & .79 & .60 & .64 & .84 \\
\hline $6 \mathrm{~g}$ & $\mathrm{CR}$ & $.1 \mathrm{mo}-50 \mathrm{y}$ & $57-14$ & .47 & .79 & .62 & $.96(1.6)$ & .92 & .88 & .97 & .97 \\
\hline $6 \mathrm{~g}$ & RG & $.1 \mathrm{mo}-50 \mathrm{y}$ & $56-22$ & .45 & .52 & .48 & $.90(.54)$ & .90 & .69 & .76 & .91 \\
\hline $6 \mathrm{i}$ & $\mathrm{CR}$ & $.1 \mathrm{mo}-50 \mathrm{y}$ & $12-6$ & .27 & .31 & .29 & $.81(.19)$ & .83 & .50 & .56 & .88 \\
\hline $6 i$ & $\mathrm{RG}$ & $.1 \mathrm{mo}-50 \mathrm{y}$ & $39-16$ & 60 & .73 & .66 & $.95(.38)$ & .91 & .88 & .94 & .97 \\
\hline 6 & wo & $.1 \mathrm{mo}-50 \mathrm{y}$ & $32-10$ & .59 & .64 & .62 & $.81(.33)$ & .78 & .75 & .78 & .83 \\
\hline$M$ & & & & .50 & .74 & .66 & 84 & .80 & .82 & .85 & .93 \\
\hline
\end{tabular}

Note. The participants were adults, and 9 points were fit. Lin $=$ linear; Hyp $=$ hyperbolic; $\operatorname{Exp}=$ exponential; Log $=\operatorname{logarithmic;} m=$ slope parameter; Pwr = power; $\mathrm{EP}=$ exponential power; $\mathrm{HP}=$ hyperbolic power; $\mathrm{Hi}=$ the highest of the 105 functions fit; $\mathrm{CR}=\mathrm{cued}$ recall; $\mathrm{FR}=$ free recall; $\mathrm{MG}=$ matching; $\mathrm{RG}=$ recognition, $\mathrm{WO}=$ word order; mo $=$ month; $\mathrm{d}=$ day; $\mathrm{y}=$ year.

${ }^{a}$ Subentries are the number of the figure or table in the study from which the data were extracted. If more than one data set was taken, a one- or twoletter code was added to distinguish them from each other.

one every few seconds. They judged whether the word presented was also presented earlier in the experiment. By varying the spacing between repetitions of a word in this continuous recognition task, retention intervals of between $1 \mathrm{~s}$ and $2 \mathrm{hr}$ were typically obtained in a single session, with intervals of up to 2 weeks achieved by having additional sessions. The participants were often undergraduates, but as mentioned earlier, people of different ages; an amnesic patient (H.M.), and students while sober or intoxicated were also tested. All results are reported in terms of the signal-detection measure, $d^{\prime}$. Unlike Bahrick's tests for the content of semantic memory of materials learned over many presentations, Wickelgren's test was for the episodic memory of whether there was a previous presentation of a wellknown word within the experimental context.

\section{Data Sets Sorted by Task and Species}

The remaining data sets are grouped thematically rather than by laboratory. Recognition and recall data sets are reported in Tables 3 and 4 . Savings and sensorimotor tasks are reported in Tables 5 and 6 . Two recognition studies require added clarification. Luh ( 1922 ) presented recognition data in three separate tables. However, the recognition data from the $100 \%$ learning condition in his Table 15 were not included in our analysis because they were the same values as the data for the second set of experiments in his Table 11. In Spitzer (1939), participants were tested two and sometimes even three times. Although repeated testing did occur, recognition monotonically decreased, and we included the data.

Studies of retention in animals are reported in Table 7 . The most common procedure for these studies is delayed matching to sample. Subjects indicate that one of two choices represents the most recently presented target stimulus. Variants exist, but in one form, animals are presented with a target stimulus (e.g., either vertical or horizontal lines) on a central key. After a brief delay, comparison stimuli (i.e., horizontal and vertical lines) appear on left and right keys, and the animal is rewarded for indicating which occurred earlier. In delayed symbolic matching to sample, the stimulus present at testing is not identical to the one initially presented but either stands for it or notes a pattern in it. These procedures and their variants have a variety of names including delayed paired comparison and delayed conditional discrimination. In one case we changed the dependent measure because the one the experimenters reported increased 
Table 2

Description of Data Sets From Wickelgren's Laboratory With Fits to Selected Functions

\begin{tabular}{|c|c|c|c|c|c|c|c|c|c|c|c|c|}
\hline \multirow[b]{2}{*}{ Study ${ }^{a}$} & \multicolumn{2}{|c|}{ Method } & \multicolumn{2}{|c|}{ Range } & \multicolumn{8}{|c|}{$r^{2}$ fit of selected functions } \\
\hline & $\mathbf{P}$ & RI & Time & $d^{\prime}$ & Lin & Hyp & Exp & $\log (m)$ & Pwr & EP & HP & $\mathrm{Hi}$ \\
\hline \multicolumn{13}{|c|}{ Begg \& Wickelgren (1974) } \\
\hline lal & $\mathrm{u}$ & 14 & $7.5 \mathrm{~s}-2 \mathrm{hr}$ & $5.0-1.8$ & .68 & .81 & .76 & $.89(.42)$ & .85 & .89 & .91 &. \\
\hline lah & $\mathrm{u}$ & 14 & $7.5 \mathrm{~s}-2 \mathrm{hr}$ & $4.4-2.3$ & .60 & .71 & .68 & $.83(.35)$ & .80 & .82 & .84 & .84 \\
\hline$|b|$ & $\mathrm{u}$ & 13 & $7.5 \mathrm{~s}-2 \mathrm{hr}$ & $4.4-1.2$ & .69 & .76 & .72 & $.82(.41)$ & .78 & .84 & .85 & .85 \\
\hline Ibh & $\mathrm{u}$ & 13 & $7.5 \mathrm{~s}-2 \mathrm{hr}$ & $4.6-1.9$ & .76 & .85 & .81 & $.83(.35)$ & .78 & .91 & .91 & .91 \\
\hline 21 & $\mathrm{u}$ & 13 & $15 \mathrm{~s}-2 \mathrm{hr}$ & $1.8-0.4$ & .57 & .81 & .68 & $.92(.21)$ & .92 & .86 & .92 & .92 \\
\hline $2 \mathrm{~h}$ & $\mathrm{u}$ & 13 & $15 \mathrm{~s}-2 \mathrm{hr}$ & $1.6-0.4$ & .63 & .80 & .72 & $.85(.17)$ & .82 & .84 & .86 & .86 \\
\hline \multicolumn{13}{|c|}{ Fajnsztejn-Pollack (1973) } \\
\hline la & $\mathrm{c}$ & 5 & $2-49 w$ & $4.0-1.4$ & .94 & .97 & .96 & $.94(.75)$ & .88 & .97 & .93 & .98 \\
\hline It & $\mathrm{c}$ & 5 & $2-49 w$ & $3.3-1.0$ & .92 & .96 & .96 & $.95(.67)$ & .88 & .96 & .93 & .98 \\
\hline 1s & $\mathrm{c}$ & 5 & $2-49 w$ & $2.6-0.6$ & .90 & 1.0 & .98 & $.99(.63)$ & .91 & .99 & .95 & 1.0 \\
\hline If & $c$ & 5 & $2-49 w$ & $2.7-0.4$ & .93 & .94 & .96 & $.94(.66)$ & .82 & .94 & .88 & .98 \\
\hline $2 a$ & $\mathrm{c}$ & 5 & $2-49 w$ & $3.0-0.9$ & .69 & .96 & .86 & $.97(.70)$ & .98 & .96 & .99 & .99 \\
\hline $2 \mathrm{t}$ & $\mathrm{c}$ & 5 & $2-49 w$ & $2.4-0.6$ & .61 & .91 & .76 & $.92(.52)$ & .99 & .91 & .98 & 1.0 \\
\hline $2 s$ & $\mathrm{c}$ & 5 & $2-49 w$ & $1.8-0.2$ & .78 & .99 & .96 & $.99(.49)$ & .96 & 1.0 & .96 & 1.0 \\
\hline $2 f$ & $\mathrm{c}$ & 5 & $2-49 w$ & $1.7-0.2$ & .84 & .99 & .96 & $1.0(.44)$ & .94 & .99 & .96 & 1.0 \\
\hline $3 a$ & $c$ & 5 & $2-49 w$ & $1.8-0.2$ & .57 & .94 & .82 & $.88(.45)$ & .97 & .92 & .98 & .98 \\
\hline $3 t$ & $\mathrm{c}$ & 5 & $2-49 w$ & $1.2-0.2$ & .27 & .82 & .64 & $.60(.26)$ & .84 & .73 & .88 & .96 \\
\hline $3 \mathrm{~s}$ & $\mathrm{c}$ & 5 & $2-49 w$ & $1.3-0.2$ & .43 & .97 & .88 & $.80(.34)$ & .98 & .93 & .99 & 1.0 \\
\hline $3 f$ & $\mathrm{c}$ & 5 & $2-49 w$ & $0.9-0.0$ & .46 & .99 & .99 & $.83(.37)$ & 1.0 & 1.0 & .98 & 1.0 \\
\hline \multicolumn{13}{|l|}{ Wickelgren (1968) } \\
\hline $1 \mathrm{sdt}$ & $\mathrm{H}$ & 6 & $1-6 \mathrm{~s}$ & $2.1-0.6$ & .87 & .92 & .95 & $.94(.95)$ & .90 & .93 & .88 & .95 \\
\hline It & $\mathrm{H}$ & 6 & $.25-4 \mathrm{~s}$ & $1.5-0.4$ & .83 & .65 & .73 & $.51(.34)$ & .43 & .59 & .69 & .99 \\
\hline \multicolumn{13}{|l|}{ Wickelgren (1972) } \\
\hline $1 \mathrm{sw}$ & $\mathrm{u}$ & 8 & $.9-23 \mathrm{~s}$ & $4.3-2.8$ & .68 & .78 & .73 & $.95(.47)$ & .97 & .88 & .92 & .98 \\
\hline ltcdw & $\mathrm{u}$ & 6 & $.9-12 \mathrm{~s}$ & $3.2-2.0$ & .78 & .85 & .82 & $.86(.61)$ & .85 & .86 & .87 & .88 \\
\hline 1 & $\mathrm{u}$ & 6 & $.9-12 \mathrm{~s}$ & $1.4-0.5$ & .73 & .90 & .82 & $.93(.36)$ & .96 & .91 & .96 & .96 \\
\hline $3 \mathrm{~h}$ & $\mathrm{u}$ & 8 & $.9-23 \mathrm{~min}$ & $6.0-5.0$ & .51 & .54 & .52 & $.83(.21)$ & .84 & .68 & .70 & .93 \\
\hline $3 \mathrm{~m}$ & $\mathrm{u}$ & 8 & $.9-23 \mathrm{~min}$ & $4.0-2.6$ & .54 & .66 & .59 & $.81(.57)$ & .83 & .74 & .79 & .84 \\
\hline 31 & $\mathrm{u}$ & 8 & $.9-23 \mathrm{~min}$ & $3.2-1.8$ & .68 & .76 & .72 & $.82(.43)$ & .81 & .80 & .82 & .82 \\
\hline $5 t$ & $\mathrm{u}$ & 12 & $5 \mathrm{~min}-7 \mathrm{hr}$ & $4.2-2.2$ & .78 & .84 & .82 & $.88(.43)$ & .87 & .88 & .89 & .89 \\
\hline $5 f$ & $\mathrm{u}$ & 12 & $5 \mathrm{~min}-7 \mathrm{hr}$ & $3.6-1.6$ & .82 & .86 & .85 & $.87(.44)$ & .85 & .88 & .88 & .88 \\
\hline $5 \mathrm{~s}$ & $\mathrm{u}$ & 12 & $5 \mathrm{~min}-7 \mathrm{hr}$ & $2.4-0.9$ & .87 & .92 & .90 & $.95(.30)$ & .92 & .95 & .95 & .96 \\
\hline $6 \mathrm{~h}$ & $\mathrm{u}$ & 15 & $5 \mathrm{hr}-14 \mathrm{~d}$ & $2.7-0.7$ & .75 & .88 & .82 & $.93(.45)$ & .90 & .91 & .93 & .93 \\
\hline 61 & $\mathrm{u}$ & 15 & $5 \mathrm{hr}-14 \mathrm{~d}$ & $1.4-0.4$ & .55 & .80 & .68 & $.84(.28)$ & .85 & .81 & .86 & .86 \\
\hline $7 \mathrm{~h}$ & $\mathrm{u}$ & 5 & $10-110 w$ & $2.8-1.3$ & .83 & .96 & .90 & $.98(.66)$ & .99 & .97 & .99 & .99 \\
\hline 71 & $\mathrm{u}$ & 5 & $10-110 w$ & $1.0-0.6$ & .76 & .86 & .82 & $.93(.18)$ & .94 & .90 & .93 & .94 \\
\hline 80 & $\mathrm{u}$ & 7 & $1-60 \mathrm{~min}$ & $1.8-1.8$ & .66 & .86 & .76 & $.97(.40)$ & .97 & .92 & .96 & .97 \\
\hline 8 to & $\mathrm{u}$ & 5 & $3-61 \mathrm{~min}$ & $3.2-1.8$ & .76 & .85 & .80 & $.98(.46)$ & 1.0 & .93 & .97 & 1.0 \\
\hline $8 \mathrm{tt}$ & $\mathrm{u}$ & 6 & $4-62 \mathrm{~min}$ & $3.0-1.4$ & .86 & .91 & .88 & $.96(.39)$ & .95 & .95 & .96 & .96 \\
\hline 8 tn & $\mathrm{u}$ & 6 & $12-70 \mathrm{~min}$ & $3.2-2.0$ & .75 & .78 & .76 & $.85(.53)$ & .86 & .82 & .84 & .89 \\
\hline \multicolumn{13}{|c|}{ Wickelgren (1974a) } \\
\hline $2 n$ & $\mathrm{u}$ & 12 & $7-700 \mathrm{~s}$ & $4.5-2.1$ & .73 & .84 & .79 & $.85(.49)$ & .82 & .87 & .87 & .87 \\
\hline \multicolumn{13}{|c|}{ Wickelgren (1975a) } \\
\hline la & $\mathrm{u}$ & 10 & $2-120 \min$ & $2.2-1.0$ & .58 & .72 & .65 & $.89(.28)$ & .93 & .80 & .87 & .95 \\
\hline le & 0 & 10 & $2-120 \min$ & $1.4-0.7$ & .44 & .57 & .50 & $.78(.18)$ & .84 & .67 & .76 & .91 \\
\hline $1 \mathrm{c}$ & $c$ & 10 & $2-120 \mathrm{~min}$ & $0.8-0.3$ & .38 & .47 & .42 & $.66(.09)$ & .74 & .55 & .62 & .88 \\
\hline \multicolumn{13}{|c|}{ Wickelgren (1975b) } \\
\hline is & $\mathrm{a}$ & 12 & $2 \mathrm{~m}-14 \mathrm{~d}$ & $2.8-0.2$ & .48 & .90 & .78 & $.94(.26)$ & 1.0 & .90 & .97 & 1.0 \\
\hline la & $\mathrm{a}$ & 12 & $2 \mathrm{~m}-14 \mathrm{~d}$ & $2.6-0.2$ & .48 & .92 & .82 & $.95(.23)$ & .99 & .92 & .98 & .99 \\
\hline$M$ & & & & & .68 & .84 & .79 & .88 & .89 & .87 & .90 & .94 \\
\hline
\end{tabular}

Note. The task was always recognition. $\mathrm{P}=$ participants; $\mathrm{RI}=$ retention interval $($ number of points fit); $\operatorname{Lin}=\mathbf{l i n e a r} ; \mathrm{Hyp}=\mathrm{hyperbolic} ; \mathrm{Exp}=$ exponential; $\log =$ logarithmic; $m=$ slope parameter; $\mathrm{Pwr}=$ power; $\mathrm{EP}=$ exponential power; $\mathrm{HP}=$ hyperbolic power; $\mathrm{Hi}=$ the highest of the 105 functions fit; $\mathrm{a}=$ adults; $\mathrm{c}=$ children; $\mathrm{H}=$ the amnesic, $\mathrm{H} . \mathrm{M} . ; 0=$ older adults; $\mathrm{u}=$ undergraduate students; $\mathrm{w}=$ weeks; $\mathrm{d}=$ days.

${ }^{a}$ Subentries are the number of the figure or table in the study from which the data were extracted. If more than one data set was taken, a one- or twoletter code was added to distinguish them from each other.

as retention decreased. After training animals to transverse a runway more quickly when a discriminative stimulus signals food, $\mathrm{S}^{+}$, than when it signals no food, $\mathrm{S}^{-}$, Alescio-Lautier and Soumireu-Mourat ( 1986) used the sum of the $\mathrm{S}^{+}$times divided by the sum of the $\mathrm{S}^{+}$times plus the $\mathrm{S}^{-}$times as their dependent measure. However the $\mathrm{S}^{+}$times increase as the animal treats the $\mathrm{S}^{+}$and $\mathrm{S}^{-}$more equally. Instead we report as the dependent measure the difference between the $S^{+}$and the $S^{-}$times, which 
Table 3

Description of Recognition Data Sets With Fits to Selected Functions

\begin{tabular}{|c|c|c|c|c|c|c|c|c|c|c|c|c|}
\hline \multirow[b]{2}{*}{ Study ${ }^{3}$} & \multicolumn{2}{|c|}{ Method } & \multicolumn{2}{|c|}{ Range } & \multicolumn{8}{|c|}{$r^{2}$ fit of selected functions } \\
\hline & $\mathbf{P}$ & RI & Time & $\%$ correct & Lin & Hyp & Exp & $\log (m)$ & Pwr & EP & HP & $\mathrm{Hi}$ \\
\hline \multicolumn{13}{|l|}{ Burtt \& Dobell (1925) } \\
\hline 1 & $\mathbf{u}$ & 5 & $5 \min -4 w$ & $88-51$ & .90 & .97 & .94 & $.85(3.8)$ & .83 & .98 & .96 & .98 \\
\hline \multicolumn{13}{|l|}{ Fioravanti \& Di Cesare (1992) } \\
\hline $2 v$ & $\mathrm{a}$ & 6 & $2-48 \mathrm{hr}$ & $82-79$ & .58 & .59 & .59 & $.89(1.4)$ & .89 & .75 & .76 & .89 \\
\hline \multicolumn{13}{|l|}{ Gehring et al. (1976) } \\
\hline $2 p$ & u & 6 & $10 \mathrm{~min}-3 \mathrm{mo}$ & $74-20$ & .61 & .84 & .73 & $.99(5.7)$ & .95 & .93 & .98 & .99 \\
\hline $2 w$ & $\mathbf{u}$ & 6 & $10 \mathrm{~min}-3 \mathrm{mo}$ & $52-14$ & .53 & .84 & .69 & $.99(4.2)$ & .95 & .91 & .98 & .99 \\
\hline $2 \mathrm{~km}$ & $\mathbf{u}$ & 5 & $4-16$ mo & $66-58$ & .97 & .98 & .98 & $1.0(.56)$ & 1.0 & 1.0 & 1.0 & 1.0 \\
\hline \multicolumn{13}{|l|}{ Glasnapp et al. (1978) } \\
\hline $2 \mathrm{kn}$ & $\mathbf{u}$ & 5 & 4-16 mo & $65-48$ & .80 & .82 & .81 & $.85(1.0)$ & .85 & .84 & .85 & .85 \\
\hline $2 \mathrm{cn}$ & $\mathrm{u}$ & 5 & $4-16 \mathrm{mo}$ & $73-60$ & .20 & .23 & .20 & $.36(.47)$ & .39 & .30 & .32 & .85 \\
\hline 2an & $\mathrm{u}$ & 5 & $4-16 \mathrm{mo}$ & $44-50$ & .81 & .82 & .82 & $.67(.17)$ & .68 & .76 & .77 & .87 \\
\hline \multicolumn{13}{|l|}{ Luh (1922) } \\
\hline 6 & $\mathrm{~g}$ & 5 & $20 \mathrm{~min}-48 \mathrm{hr}$ & $98-72$ & .89 & .93 & .91 & $.90(5.6)$ & .88 & .97 & .97 & .97 \\
\hline 11 & $\mathrm{~g}$ & 5 & $20 \mathrm{~min}-48 \mathrm{hr}$ & $96-.79$ & .78 & .82 & .80 & $.90(4.0)$ & .89 & .91 & .92 & .92 \\
\hline 150 & $\mathrm{~g}$ & 7 & $20 \mathrm{~min}-48 \mathrm{hr}$ & $98-73$ & .97 & .97 & .97 & $.87(7.0)$ & .85 & .94 & .93 & .97 \\
\hline $15 \mathrm{~s}$ & $\mathrm{~g}$ & 5 & $20 \mathrm{~min}-48 \mathrm{hr}$ & $93-62$ & .96 & .97 & .97 & $.91(6.2)$ & .88 & .98 & .98 & 1.0 \\
\hline $15 t$ & $\mathrm{~g}$ & 5 & $20 \mathrm{~min}-48 \mathrm{hr}$ & $73-26$ & .91 & .91 & .92 & $.92(8.4)$ & .89 & .94 & .93 & .96 \\
\hline \multicolumn{13}{|l|}{ Spitzer (1939) } \\
\hline la & $\mathrm{c}$ & 7 & $5 \min -63 d$ & $52-42$ & .74 & .78 & .76 & $.75(.22)$ & .73 & .94 & .95 & .95 \\
\hline $1 \mathrm{u}$ & $\mathrm{c}$ & 7 & $5 \min -63 d$ & $52-25$ & .40 & .59 & .48 & $.98(.70)$ & .97 & .79 & .88 & .98 \\
\hline \multicolumn{13}{|l|}{ Squire (1989) } \\
\hline la & $\mathrm{a}$ & 15 & $1 y-15 y$ & $77-58$ & .88 & .92 & .90 & $.96(7.9)$ & .95 & .96 & .96 & .96 \\
\hline \multicolumn{13}{|l|}{ Strong (1913) } \\
\hline 3 & a & 14 & $15 \mathrm{~s}-7 \mathrm{~d}$ & $92-57$ & .28 & .33 & .30 & $.94(2.9)$ & .92 & .60 & .67 & .95 \\
\hline$M$ & & & & & .72 & .78 & .75 & .87 & .85 & .85 & .87 & .95 \\
\hline
\end{tabular}

Note. The task was always recognition. $\mathrm{P}=$ participants; $\mathrm{RI}=$ retention interval (number of points fit); Lin $=$ linear; Hyp = hyperbolic; Exp = exponential; $\log =$ logarithmic; $m=$ slope parameter; $\mathrm{Pwr}=$ power; $\mathrm{EP}=$ exponential power; $\mathrm{HP}=$ hyperbolic power; $\mathrm{Hi}=$ the highest of the 105 functions fit; $\mathrm{a}=$ adults; $\mathrm{c}=$ children; $\mathrm{g}=$ graduate students; $\mathrm{u}=$ undergraduate students; $w=$ weeks; mo $=$ months; $d=$ days; $y=$ years.

${ }^{a}$ Subentries are the number of the figure or table in the study from which the data were extracted. If more than one data set was taken, a one- or twoletter code was added to distinguish them from each other.

is abbreviated as run time in Table 7 . Furthermore, although most animal researchers present retention data using group means, a few studies included data for individual subjects ( Jans \& Catania, 1980; Nelson \& Wasserman, 1978; White \& McKenzie, 1982). To make these studies consistent with the others and because individual data were often too noisy to meet our requirement that one fit be at least $r=.9$, we averaged data from the individual subjects for our analyses.

The miscellaneous category of Table 8 contains several data sets that require explanation. Bean (1912) and Luh (1922) used a reconstruction procedure. In this task, participants first learned a list of words. Next, they were given cards in a scrambled order with the words written on them. The participants were scored on the extent to which they reproduced the order of the words presented during learning (see Serra \& Nairne, 1993, for a recent application of this method). Conway, Cohen, and Stanhope (1991) used a grouping task in which participants categorized cognitive psychology terms of similar meanings. Rovee-Collier (1993) measured retention using the kicking rate of infants to the sight of a mobile divided by their kicking rate immediately after training with the mobile. Although implicit memory is a major area of research in which strong claims have been made about retention (see Roediger \& McDermott, 1993, for a review), the completion data sets provided by Sloman, Hayman, Ohta, Law, and Tulving (1988) are the only implicit memory data that met our criteria for inclusion. These researchers used fragment completion procedures with percentage correct as the dependent measure. An additional sixth retention interval was included in their Experiment 2, but we did not include it because it was based on much less data than the earlier five.

Several researchers adopted a dating procedure. Performance was measured by the absolute number of days away from the target date that participants dated events. Such measures increase over time because amount of dating error increases over time. Two dating data sets were included for Thompson (1982) for the same experiment because it had two different dependent measures. The mean of each participant's median dating error is the dependent measure in Thompson (1982, Experiment 2) and the mean percentage of events dated correctly is used in Thompson (1982, Experiment 2). Finally, MacLeod (1988)4 ns was included in the miscellaneous category because MacLeod (1988) used a mix of recognition and savings. The data set that met our criteria is the percentage of pictures recognized that were forgotten during the retention interval but relearned in one trial.

The autobiographical memory data sets reported in Table 9 are included here because they have been claimed to be reten- 
Table 4

Description of Recall Data Sets With Fits to Selected Functions

\begin{tabular}{|c|c|c|c|c|c|c|c|c|c|c|c|c|c|}
\hline \multirow[b]{2}{*}{ Study ${ }^{a}$} & \multicolumn{3}{|c|}{ Method } & \multicolumn{2}{|c|}{ Range } & \multicolumn{8}{|c|}{$r^{2}$ fit of selected functions } \\
\hline & $\mathbf{P}$ & Task & RI & Time & $\%$ correct & Lin & Hyp & Exp & $\log (m)$ & Pwr & EP & HP & $\mathrm{Hi}$ \\
\hline \multicolumn{14}{|l|}{ Bean (1912) } \\
\hline 6 & $\mathbf{u}$ & SR & 6 & $1-28 d$ & $89-79$ & .62 & .64 & .63 & $.92(3.3)$ & .92 & .80 & .81 & .93 \\
\hline \multicolumn{14}{|l|}{ Bregman (1968) } \\
\hline las & $\mathbf{u}$ & CR & 8 & $3-288 \mathrm{~s}$ & $80-25$ & .54 & .86 & .64 & $.92(.13)$ & .94 & .88 & .94 & 0 \\
\hline lag & u & CR & 8 & $3-288 \mathrm{~s}$ & $91-7$ & .60 & .87 & .75 & $.90(.17)$ & .94 & .88 & .94 & .94 \\
\hline 1 ap & $\mathbf{u}$ & CR & 8 & $3-288 \mathrm{~s}$ & $74-14$ & .50 & .89 & .78 & $.88(.15)$ & .91 & .88 & .92 & .93 \\
\hline lac & $\mathbf{u}$ & $\mathrm{CR}$ & 8 & $3-288 \mathrm{~s}$ & $70-3$ & .44 & .96 & .94 & $.86(.15)$ & .93 & .95 & .92 & .96 \\
\hline $1 \mathrm{bs}$ & $\mathbf{u}$ & CR & 8 & $3-288 \mathrm{~s}$ & $92-14$ & .47 & .92 & .78 & $.87(.17)$ & .97 & .89 & .97 & .97 \\
\hline $1 \mathrm{bg}$ & $\mathbf{u}$ & CR & 8 & $3-288 \mathrm{~s}$ & $88-17$ & .53 & .84 & .73 & $.89(.14)$ & .95 & .86 & .94 & .95 \\
\hline $1 \mathrm{bp}$ & $\mathbf{u}$ & $\mathrm{CR}$ & 8 & $3-288 \mathrm{~s}$ & $86-12$ & .50 & .85 & .67 & $.86(.15)$ & .95 & .84 & .94 & .96 \\
\hline $1 b c$ & u & $\mathrm{CR}$ & 8 & $3-288 \mathrm{~s}$ & $78-1$ & .28 & .96 & .98 & $.68(.14)$ & .96 & .96 & .93 & .98 \\
\hline \multicolumn{14}{|l|}{ Burtt \& Dobell (1925) } \\
\hline 1 & $\mathbf{u}$ & $\mathrm{CR}$ & 5 & $5 \min -4 w$ & $43-2$ & .59 & 1.0 & .99 & $1.0(4.7)$ & .99 & 1.0 & .99 & 1.0 \\
\hline \multicolumn{14}{|l|}{ Conway et al. (1991) } \\
\hline $2 \mathrm{c}$ & a & $\mathrm{CR}$ & 12 & $3-125 \mathrm{mo}$ & $60-75$ & .60 & .81 & .70 & $.93(9.5)$ & .95 & .87 & .93 & .9 \\
\hline \multicolumn{14}{|l|}{ Fioravanti \& Di Cesare (1992) } \\
\hline $2 s$ & a & SR & 7 & $5 \mathrm{~min}-48 \mathrm{hr}$ & $97-68$ & .91 & .94 & .93 & $.69(2.6)$ & .67 & .92 & .91 & .95 \\
\hline Krueger (1929) & & & & & & & & & & & & & \\
\hline 20 & $\mathrm{~g}$ & AR & 6 & $1-28 d$ & $26-0$ & .43 & .97 & 1.0 & $.81(1.2)$ & .98 & .99 & .94 & 1.0 \\
\hline $20 f$ & $g$ & AR & 6 & $1-28 \mathrm{~d}$ & $38-2$ & .65 & .99 & .98 & $.96(1.4)$ & .97 & 1.0 & .95 & 1.0 \\
\hline $2 t$ & $\mathrm{~g}$ & $\mathrm{AR}$ & 6 & $1-28 d$ & $49-3$ & .69 & .98 & .98 & $.97(1.7)$ & .95 & .99 & .94 & 1.0 \\
\hline Lavach (1971) & & & & & & & & & & & & & \\
\hline 11 & $\mathrm{u}$ & CR & 5 & $5 \mathrm{~min}-30 \mathrm{~d}$ & $36-1$ & .76 & .80 & .78 & $.84(.18)$ & .82 & .84 & .83 & .87 \\
\hline Longmore \& Knight (1988) & & & & & & & & & & & & & \\
\hline lc & a & FR & 5 & $.1-18 \mathrm{~s}$ & $100-45$ & .82 & .97 & .91 & $.92(3.0)$ & .87 & .98 & .96 & .98 \\
\hline $1 \mathrm{~d}$ & a & FR & 5 & $.1-18 \mathrm{~s}$ & $100-7$ & .82 & .98 & 1.0 & $.94(5.1)$ & .86 & .97 & .90 & 1.0 \\
\hline $1 \mathrm{k}$ & a & FR & 5 & $.1-18 \mathrm{~s}$ & $100-13$ & .75 & .99 & .97 & $.98(4.8)$ & .92 & .99 & .95 & .99 \\
\hline Luh (1922) & & & & & & & & & & & & & \\
\hline 6 & $\mathrm{~g}$ & AR & 5 & $20 \mathrm{~min}-48 \mathrm{hr}$ & $68-10$ & .78 & .96 & .90 & $.99(11)$ & .97 & .98 & .98 & .9 \\
\hline 6 & $\mathrm{~g}$ & SR & 5 & $20 \mathrm{~min}-48 \mathrm{hr}$ & $88-27$ & .84 & .96 & .91 & $.99(13)$ & .94 & .99 & .99 & .5 \\
\hline 11 & $\mathrm{~g}$ & SR & 5 & $20 \mathrm{~min}-48 \mathrm{hr}$ & $91-40$ & .78 & .90 & .84 & $.98(11)$ & .97 & .96 & .98 & .9 \\
\hline 150 & $\mathrm{~g}$ & SR & 7 & $20 \mathrm{~min}-48 \mathrm{hr}$ & $88-31$ & .80 & .97 & .91 & $.98(20)$ & .96 & .98 & .98 &.$S$ \\
\hline $15 \mathrm{~s}$ & $\mathrm{~g}$ & SR & 5 & $20 \mathrm{~min}-48 \mathrm{hr}$ & $86-25$ & .92 & .97 & .96 & $.96(11)$ & .91 & .98 & .97 & .9 \\
\hline $15 \mathrm{t}$ & $\mathrm{g}$ & SR & 5 & $20 \mathrm{~min}-48 \mathrm{hr}$ & $68-14$ & .84 & .94 & .90 & $.99(10)$ & .96 & .97 & .98 & 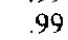 \\
\hline Murdock (1961) & & & & & & & & & & & & & \\
\hline 1c & $\mathrm{u}$ & FR & 6 & $1-18 \mathrm{~s}$ & $94-16$ & .79 & .96 & .97 & $.95(30)$ & .89 & .96 & .89 & .98 \\
\hline $1 w$ & $\mathrm{u}$ & FR & 6 & $1-18 \mathrm{~s}$ & $98-84$ & .92 & .93 & .93 & $.75(5.2)$ & .73 & .87 & .86 & , \\
\hline lwt & $\mathrm{u}$ & FR & 6 & $1-18 \mathrm{~s}$ & $93-23$ & .74 & .97 & .92 & $.95(26)$ & .93 & .96 & .94 & .97 \\
\hline $3 z$ & $\mathrm{u}$ & $\mathrm{FR}$ & 6 & $1-18 s$ & $100-91$ & .90 & .90 & .90 & $.84(.03)$ & .84 & .91 & .91 & .93 \\
\hline 3th & $\mathbf{u}$ & FR & 6 & $1-18 \mathrm{~s}$ & $100-82$ & .63 & .69 & .66 & $.84(.08)$ & .84 & .79 & .81 & .84 \\
\hline 3s & $\mathrm{u}$ & FR & 6 & $1-18 s$ & $98-80$ & .92 & .95 & .94 & $.98(.06)$ & .97 & .99 & 1.0 & 1.0 \\
\hline $3 \mathbf{n}$ & $\mathrm{u}$ & FR & 6 & $1-18 \mathrm{~s}$ & $98-83$ & .82 & .86 & .84 & $.93(.06)$ & .92 & .93 & .94 & .94 \\
\hline $3 \mathrm{t}$ & $\mathrm{u}$ & FR & 6 & $1-18 s$ & $97-82$ & .80 & .83 & .82 & $.86(.06)$ & .86 & .88 & .88 & 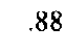 \\
\hline Nelson et al. (1980) & & & & & & & & & & & & & \\
\hline la & $\mathrm{u}$ & CR & 5 & $1-7 w$ & $42-14$ & .82 & .94 & .94 & $.94(15)$ & .93 & .94 & .90 & .95 \\
\hline Peterson \& Peterson (1959) & & & & & & & & & & & & & \\
\hline 3 & $\mathrm{u}$ & FR & 6 & $3-15 \mathrm{~s}$ & $53-5$ & .92 & .90 & .98 & $.97(.29)$ & .89 & .94 & .84 & 1.0 \\
\hline Rubin (1989) & & & & & & & & & & & & & \\
\hline 1 & $\mathrm{a}$ & FR & 11 & $.1-2.3 y$ & $37-1$ & .85 & .93 & .93 & $.95(10)$ & .88 & .94 & .88 &. \\
\hline Runquis & & & & & & & & & & & & & \\
\hline $1 \mathrm{tt}$ & $\mathbf{u}$ & $\mathrm{CR}$ & 6 & $20 \mathrm{~min}-21 \mathrm{~d}$ & $100-33$ & .93 & .98 & .98 & $.73(8.7)$ & .58 & .94 & .86 & .9 \\
\hline lot & $\mathrm{u}$ & $\mathrm{CR}$ & 6 & $20 \mathrm{~min}-21 \mathrm{~d}$ & $98-57$ & .65 & .80 & .70 & $.65(6.9)$ & .56 & .82 & .82 & 0 \\
\hline ltu & $\mathrm{u}$ & $\mathrm{CR}$ & 6 & $20 \min -21 \mathrm{~d}$ & $89-17$ & .63 & .94 & .88 & $.95(11)$ & .85 & .98 & .98 & .98 \\
\hline lou & $\mathrm{u}$ & $\mathrm{CR}$ & 6 & $20 \mathrm{~min}-21 \mathrm{~d}$ & $75-21$ & .41 & .58 & .81 & $.86(9.2)$ & 81 & .88 & .85 & .9 \\
\hline Schonfield $(1969)^{\mathrm{b}}$ & & & & & & & & & & & & & \\
\hline 1 ya & $\mathbf{a}$ & FR & 5 & $.5-18 \mathrm{~s}$ & $93-18$ & .61 & .93 & .79 & $.92(22)$ & .94 & .94 & .92 & .9 \\
\hline lea & $\mathbf{a}$ & FR & 5 & $.5-18 \mathrm{~s}$ & $66-10$ & .61 & .91 & .90 & $.91(17)$ & .90 & .93 & .83 & \\
\hline al. (1970) & & & & & & & & & & & & & \\
\hline $1 \mathrm{p}$ & $\mathrm{u}$ & CR & 5 & $5 \min -4 w$ & $30-7$ & .92 & .96 & .97 & $.84(.29)$ & .80 & .94 & .90 & .98 \\
\hline ln & $\mathbf{u}$ & CR & 5 & $5 \min -4 w$ & $41-7$ & .94 & .96 & .98 & $.81(.30)$ & .77 & .93 & .87 & \\
\hline Turvey \& Weeks (197 & & & & & & & & & & & & & \\
\hline 1 & $\mathrm{u}$ & FR & 6 & $1-25 s$ & $92-27$ & .59 & .89 & .82 & $.86(.23)$ & .85 & .88 & .86 & .89 \\
\hline $3 \mathrm{~s}$ & $\mathrm{u}$ & FR & 5 & $2-30 \mathrm{~s}$ & $91-42$ & .47 & .50 & .49 & $.72(.05)$ & .75 & .60 & .63 & .89 \\
\hline $3 z$ & $\mathbf{u}$ & FR & 5 & $2-30 s$ & $68-51$ & .47 & .70 & .55 & $.76(.20)$ & .82 & .72 & .81 & s \\
\hline
\end{tabular}


Table 4 (continued)

\begin{tabular}{|c|c|c|c|c|c|c|c|c|c|c|c|c|c|}
\hline \multirow[b]{2}{*}{ Study ${ }^{a}$} & \multicolumn{3}{|c|}{ Method } & \multicolumn{2}{|c|}{ Range } & \multicolumn{8}{|c|}{$r^{2}$ fit of selected functions } \\
\hline & $\mathbf{P}$ & Task & RI & Time & $\%$ correct & Lin & Hyp & $\operatorname{Exp}$ & $\log (m)$ & $P_{W T}$ & EP & HP & $\mathrm{Hi}$ \\
\hline \multicolumn{14}{|c|}{ Waugh \& Norman (1965) } \\
\hline 10 & $\mathrm{u}$ & $\mathrm{CR}$ & 9 & $1-12 \mathrm{~s}$ & $95-1$ & .87 & .93 & .97 & $.95(.35)$ & .86 & .94 & .85 & .97 \\
\hline If & $\mathrm{u}$ & $\mathrm{CR}$ & 9 & $.5-18 \mathrm{~s}$ & $93-14$ & .88 & .81 & .93 & $.90(.45)$ & .56 & .85 & .71 & .98 \\
\hline \multicolumn{14}{|c|}{ Wixted \& Ebbeson (1991) } \\
\hline If & $\mathbf{u}$ & FR & 5 & $2.5-40 \mathrm{~s}$ & $77-55$ & .76 & .82 & .79 & $.98(.08)$ & .99 & .91 & .94 & 1.0 \\
\hline 10 & $\mathrm{u}$ & FR & 5 & $2.5-40 \mathrm{~s}$ & $58-40$ & .75 & .83 & .79 & $.97(.06)$ & .98 & .91 & .94 & .99 \\
\hline$M$ & & & & & & .71 & .89 & .86 & .89 & .88 & .91 & .90 & .96 \\
\hline
\end{tabular}

Note. $\mathrm{P}=$ participants; $\mathrm{RI}=$ retention interval (number of points fit) $\operatorname{Lin}=$ linear; Hyp $=$ hyperbolic; Exp $=\operatorname{exponential;~}$ Log $=\operatorname{logarithmic} ; m=$ slope parameter; Pwr $=$ power; $\mathrm{EP}=$ exponential power; $\mathrm{HP}=$ hyperbolic power; $\mathrm{Hi}=$ the highest of the 105 functions fit: $\mathrm{a}=\mathrm{adults} ; \mathrm{g}=\mathrm{graduate}$ students; $\mathrm{u}=$ undergraduates; $\mathrm{AR}=$ anticipation recall; $\mathrm{CR}=$ cued recall; $\mathrm{FR}=$ free recall; $\mathrm{SR}=$ serial recall; $\mathrm{d}=\mathrm{days} ; \mathrm{w}=\mathrm{weeks} ; \mathrm{mo}=$ months; $\mathrm{y}=$ years.

${ }^{a}$ Subentries are the number of the figure or table in the study from which the data were extracted. If more than one data set was taken, a one- or twoletter code was added to distinguish them from each other.

${ }^{b}$ Cited in Kausler (1982, p. 434).

tion functions (Conway \& Rubin, 1993; Rubin, 1982; Rubin, Wetzler, \& Nebes, 1986). Each has different methods and analyses, but in all of them undergraduates or older adults were asked to recall autobiographical memories from their lives and later were asked to date them. These memories were then sorted into time bins, such as decades, or 20 equal intervals on a logarithmic scale spanning the participants' lives, or the time markers used in English (e.g., 1 to $24 \mathrm{hrs}, 1$ to 7 days, . . . 1 to 70 years). For each bin in the resulting histogram, two measures were obtained: the number of memories per hour and time. If it is assumed that on the average people encode an equal number of memories each day of their lives, these values are a retention function. In previous studies, such data sets were fit well by a power function and better by it than by the other classic twoparameter retention functions, agreeing with what Wickelgren had claimed for laboratory retention at the time (Rubin, 1982).

\section{The Functions}

Psychologists have suggested many functions to describe the monotonic loss of information with time. Five of the most commonly considered functions are the linear, hyperbolic, exponential, logarithmic, and power functions. In the form used here, all are two-parameter functions, but in many curve-fitting situations each function has only one free parameter because there is often the added constraint that the immediate recall be set to $100 \%$ or that the area under the curve equals the total amount recalled.

\section{Linear}

The simplest function is $y=-m \cdot t+b$. In theory, there is an added condition. For $t>b / m, y=0$, which prevents negative values of $y$ for large values of $t$. In actual curve-fitting procedures, negative observed values of $y$ never occur, so the function without the restrictions rarely becomes negative over the range of times to which it is applied. Having degrees of unobserved negative values that are expressed behaviorally as not remembering can be useful in situations in which the same added retrieval cue can produce retrieval at short but not long intervals.
A problem with such use of negative values, however, is in defining where the "true zero" of no prior learning would be (W. Wickelgren, personal communication, January 1996). Similar constraints and boundary conditions occur with many two-parameter functions, either at large values of $t$ or an $t=0$. The positive constant, $m$, is the slope, and larger values of $m$ indicate a more rapid loss of memory. The equation can be used successfully over short intervals of time, but because retention functions typically drop more rapidly over their shorter retention intervals, it does not fit data well over the complete range from initial recall to when recall approaches zero.

\section{Hyperbolic}

The function $y=1 /(m \cdot t+b)$-or alternatively, $y=m /(t$ $+b$ ) -appears most often in studies of animal learning (e.g., Harnett, McCarthy, \& Davison, 1984; Staddon, 1983, Equation 12.1). If a visual perception metaphor is used with time, $t$, being the distance; the height, $s$, being the strength of the memory; the size of the projected image, $y$, on the retina being its probability of recall; and the retina at a distance, $e$, from the present; then $y$ shrinks with time according to the single-parameter hyperbolic function, $y=1 / m t$, where $m=e \cdot s$, as shown in Figure 2 (see Staddon, 1983, for this idea in terms of duration instead of strength).

A plausible mechanism for the hyperbola follows from the idea, based on interference theory, that items can be recalled to the extent that they can be distinguished from all other items in memory (Rubin, 1995). The idea of inability to distinguish the target has been applied to the temporal dimension by Bjork and Whitten (1974), Glenberg and Swanson (1986), and Turvey,

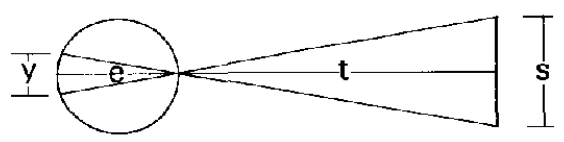

Figure 2. A graphic derivation for a hyperbolic function based on a perceptual metaphor of memory. 
Table 5

Descriptions of Savings Data Sets With Fits to Selected Functions

\begin{tabular}{|c|c|c|c|c|c|c|c|c|c|c|c|c|}
\hline \multirow[b]{2}{*}{ Study ${ }^{a}$} & \multicolumn{2}{|c|}{ Method } & \multicolumn{2}{|c|}{ Range } & \multicolumn{8}{|c|}{$r^{2}$ fit of selected functions } \\
\hline & $\mathrm{P}$ & RI & Time & Savings & Lin & Hyp & Exp & $\log (m)$ & Pwr & $\mathrm{EP}$ & HP & $\mathrm{Hi}$ \\
\hline \multicolumn{13}{|l|}{ Boreas (1930) } \\
\hline 2 & $\mathbf{a}$ & 11 & $10 \mathrm{~min}-10 \mathrm{mo}$ & $82-0$ & .66 & .87 & .85 & $.88(4.7)$ & .80 & .94 & .91 & .92 \\
\hline 3 & $\mathrm{a}$ & 12 & $9 \mathrm{hr}-2 \mathrm{y}$ & $67-32$ & .43 & .69 & .47 & $.86(6.3)$ & .81 & .80 & .89 & .95 \\
\hline Ebbinghaus (1885/1964) & $\mathbf{s}$ & 7 & $19 \min -31 \mathrm{~d}$ & $58-21$ & .35 & .51 & .40 & $.94(4.5)$ & .98 & .69 & .82 & .98 \\
\hline \multicolumn{13}{|l|}{ Finkenbinder (1913) } \\
\hline$\frac{2}{2}$ & a & 11 & $30 \mathrm{~min}-72 \mathrm{~h}$ & $75-52$ & .82 & .87 & .84 & $.96(4.3)$ & .95 & .96 & .97 & .97 \\
\hline \multicolumn{13}{|l|}{ Krueger (1929) } \\
\hline 30 & $\mathrm{~g}$ & 6 & $1-28 \mathrm{~d}$ & $22-2$ & .38 & .96 & .98 & $.77(6.0)$ & .96 & .98 & .94 & .99 \\
\hline $3 \circ f$ & $\mathrm{~g}$ & 6 & $1-28 d$ & $36-20$ & .65 & .81 & .73 & $.93(5.3)$ & .95 & .88 & .93 & .95 \\
\hline $3 t$ & $\mathrm{~g}$ & 6 & $1-28 d$ & $47-25$ & .54 & .72 & .62 & $.90(7.1)$ & .94 & .81 & .89 & .96 \\
\hline \multicolumn{13}{|l|}{ Luh (1922) } \\
\hline 6 & $\mathrm{~g}$ & 5 & $20 \mathrm{~min}-48 \mathrm{hr}$ & $75-48$ & .62 & .66 & .64 & $.93(5.1)$ & .96 & .79 & .82 & .98 \\
\hline \multicolumn{13}{|l|}{ Radosavljevich (1907) } \\
\hline $2 \mathrm{nb}^{\mathrm{b}}$ & $\mathbf{a}$ & 11 & $5 \min -120 \mathrm{~d}$ & $98-3$ & .57 & .81 & .80 & $.86(7.7)$ & .80 & .85 & .84 & .89 \\
\hline$M$ & & & & & .56 & .77 & .70 & .89 & .90 & .85 & .89 & .96 \\
\hline
\end{tabular}

Note. The task was always relearning. $\mathrm{P}=$ participants; $\mathrm{RI}=$ retention interval (number of points fit); Lin $=$ linear; Hyp $=$ hyperbolic; Exp $=$ exponential; $\log =$ logarithmic; $m=$ slope parameter; $\mathrm{Pwr}=$ power; $\mathrm{EP}=$ exponential power; $\mathrm{HP}=$ hyperbolic power; $\mathrm{Hi}=$ the highest of the 105 functions fit; $\mathrm{a}=$ adults; $\mathbf{g}=$ graduate students; $\mathbf{s}=$ self.

${ }^{a}$ Subentries are the number of the figure or table in the study from which the data were extracted. If more than one data set was taken, a one- or twoletter code was added to distinguish them from each other.

${ }^{\mathrm{b}}$ Taken from Finkenbinder (1913).

Brick, and Osborne (1970) and has been used by Baddeley (1990) to argue that the 30 -s duration of short-term memory is really an artifact of how the measurements are made. Assume that nontarget items are recorded uniformly over time at a rate of one every $a$ seconds and that among them, at time $t$ ago, was the target item. Assume, to simplify the proof, that all items recorded are of equal strength and are equal in strength to the target event under the experimental cuing conditions. Moreover, assume Weber's law for the limits of temporal discrimination such that the window of error in judging the time ago that an event occurred is $c \cdot t$, where $c$ is a positive constant (Bjork \& Whitten, 1974; Rubin \& Baddeley, 1989). The number of nontarget items in the window for lack of temporal discrimination that could be confused with the target item is $c \cdot t / a$. The probability of recalling the target, $y$, is equal to one over the total number of items in the lack-of-discrimination window. If we let $m=c / a$, then $y=1 /(m \cdot t+1)$, which is a hyperbolic with one free parameter. This form of the hyperbolic function is similar to the one on which Laming (1992) based his theory of shortterm retention.

Table 6

Description of Sensorimotor Data Sets With Fits to Selected Functions

\begin{tabular}{|c|c|c|c|c|c|c|c|c|c|c|c|c|}
\hline \multirow[b]{2}{*}{ Study ${ }^{\mathrm{a}}$} & \multicolumn{2}{|c|}{ Method } & \multicolumn{2}{|c|}{ Range } & \multicolumn{8}{|c|}{$r^{2}$ fit of selected functions } \\
\hline & Task & RI & Time & Savings & Lin & Hyp & Exp & $\log (m)$ & Pwr & EP & HP & $\mathrm{Hi}$ \\
\hline \multicolumn{13}{|c|}{ Ammons et al. (1958) } \\
\hline If & MS & 6 & $1 \mathrm{~min}-704 \mathrm{~d}$ & $68-6$ & .74 & .78 & .80 & $.85(3.9)$ & .68 & .90 & .92 & .95 \\
\hline It & MS & 6 & $1 \min -695 d$ & $92-70$ & .41 & .42 & .43 & $.92(1.8)$ & 91 & .69 & .69 & .97 \\
\hline 20 & $\mathrm{TR}$ & 5 & $21 \mathrm{hr}-706 \mathrm{~d}$ & $100-57$ & .59 & .70 & .64 & $.99(6.6)$ & .99 & .86 & .90 & .99 \\
\hline $2 \mathrm{e}$ & $\mathrm{TR}$ & 5 & $22 \mathrm{hr}-884 \mathrm{~d}$ & $100-90$ & .87 & .87 & .87 & $.87(1.3)$ & .86 & .92 & .92 & .94 \\
\hline \multicolumn{13}{|l|}{ Bean (1912) } \\
\hline $14^{\mathrm{b}}$ & $\mathrm{TP}$ & 7 & $1-35 \mathrm{~d}$ & $83-15$ & .90 & .97 & .96 & $.96(19)$ & .88 & .97 & .92 & .98 \\
\hline \multicolumn{13}{|l|}{ Tsai (1924) } \\
\hline 2 & $\mathrm{MZ}$ & 6 & $1-9 w$ & $81-50$ & .91 & .94 & .92 & $.94(14)$ & .93 & .95 & .94 & .95 \\
\hline$M$ & & & & & .74 & .78 & .77 & .92 & .88 & .88 & .88 & .96 \\
\hline
\end{tabular}

Note. The participants were undergraduates. RI = retention interval (number of points fit); Lin = linear; Hyp $=$ hyperbolic; Exp = exponential; $\log \cdots$ Logarithmic; $m=$ slope parameter; $\mathrm{Pwr}=$ power; $\mathrm{EP}=$ exponential power; $\mathrm{HP}=$ hyperbolic power; $\mathrm{Hi}=$ the highest of the 105 functions fit; $\mathrm{MS}=$ motor skill; $\mathrm{MZ}=$ maze; $\mathrm{TR}=$ tracking; $\mathrm{TP}=$ typing; $\mathrm{d}=$ days; $\mathrm{w}=$ weeks

"Subentries are the number of the figure or table in the study from which the data werc extracted. If morc than one data set was taken, a one- or twoletter code was added to distinguish them from each other.

${ }^{b}$ The dependent measure in this study was percentage correct, not savings. 
Table 7

Description of Data Sets From Tests Using Animals With Fits to Selected Functions

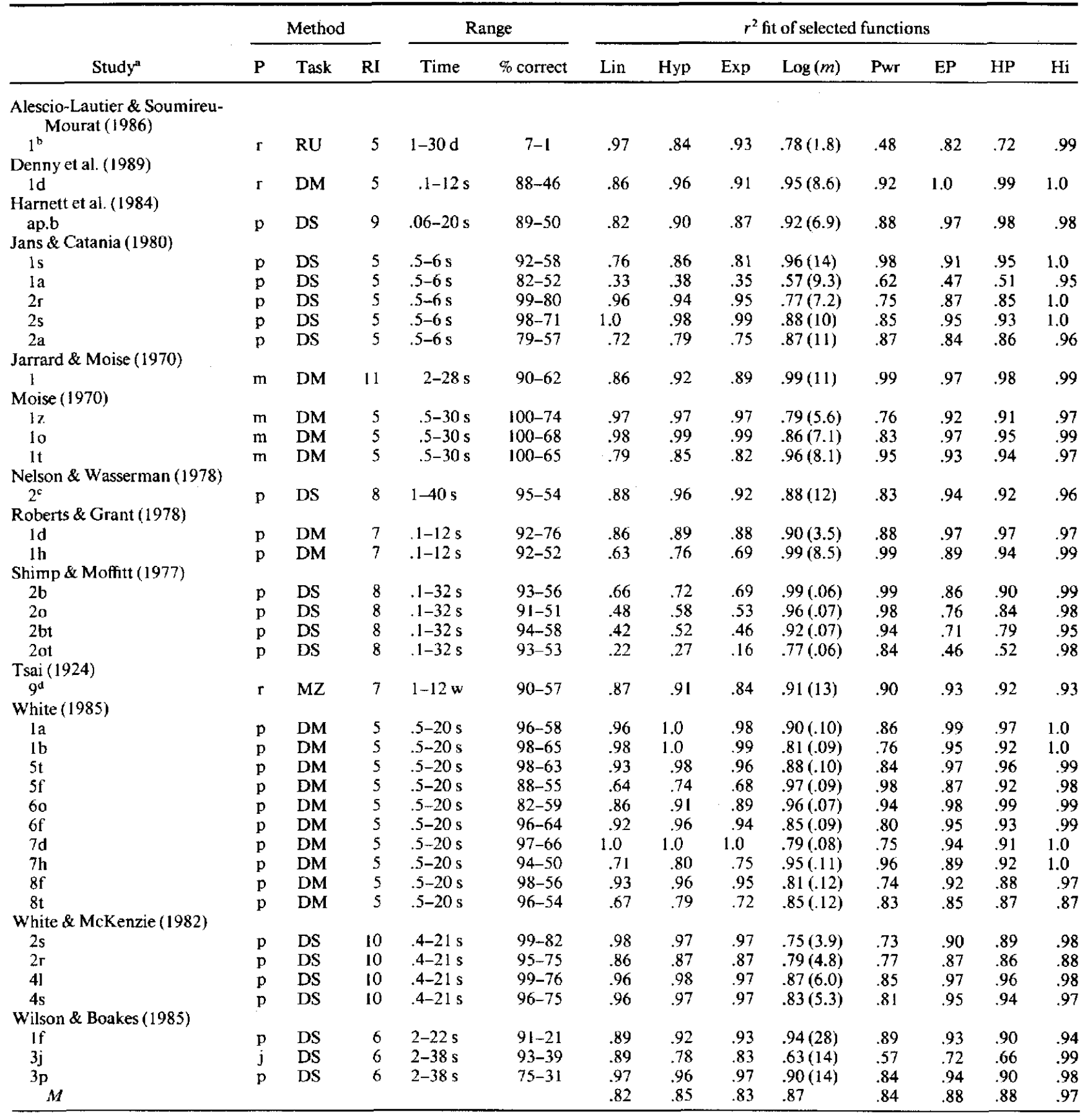

Note. $\mathbf{P}=$ participants; RI = retention interval (number of points fit $) ; \operatorname{Lin}=$ linear $; \mathrm{Hyp}=$ hyperbolic; Exp = exponential $;$ Log $=$ logarithmic; $m=$ slope parameter; $P w r=$ power; $\mathrm{EP}=$ exponential power; $\mathrm{HP}=$ hyperbolic power; $\mathrm{Hi}=$ the highest of the 105 functions fit; $\mathrm{j}=\mathrm{jackdaws} ; \mathrm{m}=$ primates; $p=$ pigeons; $r=$ rats; $D M=$ delayed matching to sample; $D S=$ symbolic delayed matching to sample; $M Z=$ maze; $R U=r u n$ time; $d=$ day.

a Subentries are the number of the figure or table in the study from which the data were extracted. If more than one data set was taken, a one- or twoletter code was added to distinguish them from each other.

${ }^{b}$ The dependent measure is the difference in running times.

c The dependent measure is a discrimination index.

${ }^{d}$ The dependent measure is savings. 
Table 8

Description of Miscellaneous Data Sets With Fits to Selected Functions

\begin{tabular}{|c|c|c|c|c|c|c|c|c|c|c|c|c|c|}
\hline \multirow[b]{2}{*}{ Study ${ }^{a}$} & \multicolumn{3}{|c|}{ Method } & \multicolumn{2}{|c|}{ Range } & \multicolumn{8}{|c|}{$r^{2}$ fit of selected functions } \\
\hline & $\mathrm{P}$ & Task & $\mathrm{RI}$ & Time & $\%$ correct & Lin & Hyp & Exp & $\log (m)$ & Pwr & $\mathrm{EP}$ & HP & $\mathbf{H i}$ \\
\hline \multicolumn{14}{|l|}{ Bean (1912) } \\
\hline & $\mathrm{u}$ & $\mathrm{SG}$ & 6 & $1-28 d$ & $89-77$ & .70 & .71 & .70 & $.91(3.2)$ & .91 & .82 & .83 & .92 \\
\hline Conway et al. (1991) & a & GR & 12 & $3-125 \mathrm{mo}$ & $57-35$ & .46 & .57 & .49 & $.79(6.5)$ & .82 & .69 & .75 & .84 \\
\hline King (1963a) & & & & & & & & & & & & & \\
\hline $\begin{array}{l}11 \\
\text { King (1963b) }\end{array}$ & $\mathbf{u}$ & $\mathrm{RP}$ & 6 & $2 \min -28 d$ & $92-78$ & .61 & .65 & .63 & $.76(1.6)$ & .75 & .79 & .80 & .84 \\
\hline $\begin{array}{l}\text { If } \\
\text { Iinton (1975) }\end{array}$ & $\mathbf{u}$ & RP & 6 & $2 \min -28 d$ & $81-59$ & .23 & .20 & .16 & $.05(.58)$ & .01 & .12 & .11 & .88 \\
\hline $\begin{array}{c}14^{\mathrm{h}} \\
\operatorname{Iuh}(1922)\end{array}$ & $\mathrm{s}$ & DT & 8 & $2-192 d$ & $0-10$ & .55 & .30 & .41 & $.89(-3.3)$ & .77 & .57 & .45 & .98 \\
\hline 6 & $\mathrm{~g}$ & $\mathrm{CN}$ & 5 & $20 \mathrm{~min}-48 \mathrm{hr}$ & $92-39$ & .91 & .98 & .96 & $.96(11)$ & .90 & 1.0 & .99 & 1.0 \\
\hline 11 & $\mathrm{~g}$ & $\mathrm{CN}$ & 5 & $20 \mathrm{~min}-48 \mathrm{hr}$ & $89-44$ & .84 & .95 & .90 & $.94(10)$ & .90 & .98 & .98 & .98 \\
\hline 150 & $\mathrm{~g}$ & $\mathrm{CN}$ & 7 & $20 \mathrm{~min}-48 \mathrm{hr}$ & $88-44$ & .80 & .88 & .86 & $.83(17)$ & .78 & .86 & .83 & .88 \\
\hline $15 \mathrm{~s}$ & $\mathrm{~g}$ & $\mathrm{CN}$ & 5 & $20 \mathrm{~min}-48 \mathrm{hr}$ & $92-32$ & .87 & .88 & .88 & $.92(10)$ & .90 & .92 & .92 & .94 \\
\hline $15 \mathrm{t}$ & $\mathrm{g}$ & $\mathrm{CN}$ & 5 & $20 \mathrm{~min}-48 \mathrm{hr}$ & $76-20$ & .79 & .95 & .88 & $1.0(11)$ & .98 & .98 & 1.0 & 1.0 \\
\hline MacLeod (1988) & & & & & & & & & & & & & \\
\hline $4 \mathrm{~ns}$ & $\mathbf{u}$ & RG & 5 & $2-10 w$ & $91-86$ & .80 & .79 & .79 & $.71(.08)$ & .69 & .76 & .74 & .92 \\
\hline $\begin{array}{l}\text { Rovee-Collier (1993) } \\
4^{c}\end{array}$ & b & KR & 11 & $.84-28 \mathrm{~d}$ & $94-35$ & .71 & .85 & .83 & $.79(.25)$ & .71 & .83 & .77 & .88 \\
\hline Rubin \& Baddeley (1989) & & & & & & & & & & & & & \\
\hline $\begin{array}{l}2^{\mathrm{b}} \\
\text { Sloman et al. (1988) }\end{array}$ & $\mathrm{a}$ & DT & 5 & $.27-2.2 y$ & $78-359$ & .99 & .89 & .97 & $.91(-126)$ & .98 & .99 & .94 & .99 \\
\hline $2 \Gamma$ & $\mathbf{u}$ & $\mathrm{CM}$ & 14 & $14-196 \mathrm{~s}$ & $85-70$ & .85 & .83 & .84 & $.70(.05)$ & .69 & .79 & .78 & .87 \\
\hline $2 \mathrm{t}$ & $\mathbf{u}$ & $\mathrm{CM}$ & 5 & $18 \min -23 w$ & $27-4$ & .64 & .89 & .79 & $.98(.02)$ & .93 & .96 & .98 & .99 \\
\hline Thompson (1982) & & & & & & & & & & & & & \\
\hline $1^{b}$ & $\mathbf{u}$ & DT & 5 & $1.6-12 w$ & $2-15$ & .99 & .83 & .91 & $.97(-6.2)$ & .99 & .96 & .89 & 1.0 \\
\hline 2 & $\mathbf{u}$ & DT & 9 & $3 d-13 w$ & $67-9$ & .66 & .97 & .85 & $.95(16)$ & .98 & .96 & .98 & .98 \\
\hline$M$ & & & & & & .73 & .77 & .76 & .83 & .81 & .82 & .81 & .93 \\
\hline
\end{tabular}

Note. $\quad \mathrm{P}=$ participants; RI = number of points fit; $\mathrm{Lin}=$ linear; Hyp $=$ hyperbolic; $\operatorname{Exp}=$ exponential; $\log =\operatorname{logarithmic} ; m=$ slope parameter $\mathrm{P}_{\mathrm{WI}}=$ power; $\mathrm{EP}=$ exponential power; $\mathrm{HP}=$ hyperbolic power; $\mathrm{Hi}=$ the highest of the 105 functions fit; $\mathrm{a}=\mathrm{adults} ; \mathrm{b}=\mathrm{babies} ; \mathrm{g}=\mathrm{graduate}$ students; $\mathrm{s}=$ self; $\mathrm{u}=$ undergraduates; $\mathrm{d}=$ days; $\mathrm{mo}=$ months; $\mathrm{w}=$ weeks, $\mathrm{y}=$ years; $\mathrm{CM}=$ completion; $\mathrm{CN}=$ reconstruction; $\mathrm{DT}=\mathrm{dating} ; \mathrm{GR}=$ grouping; $K R=$ kicking rate; $R G=$ recognition; $R P=$ reproduction; $S G=$ serial recognition.

${ }^{a}$ Subentries are the number of the figure or table in the study from which the data were extracted. If more than one data set was taken, a one- or twoletter code was added to distinguish them from each other. ${ }^{b}$ The dependent measure is absolute error in days. "The dependent measure is the ratio of kicking rate to rate at training.

Table 9

Descriptions of Autobiographical Memory Data Sets With Fits to Selected Functions

\begin{tabular}{|c|c|c|c|c|c|c|c|c|c|c|c|c|}
\hline \multirow[b]{2}{*}{ Study ${ }^{a}$} & \multicolumn{2}{|c|}{ Methods } & \multicolumn{2}{|c|}{ Range } & \multicolumn{8}{|c|}{$r^{2}$ fit of selected functions } \\
\hline & $\mathbf{P}$ & RI & Time & Frequency & Lin & Hyp & Exp & $\log (m)$ & Pwr & EP & HP & $\mathrm{Hi}$ \\
\hline \multicolumn{13}{|c|}{ Crovitz \& Schiffman (1974) } \\
\hline$\stackrel{1}{\text { Rubin }(1982)}$ & $\mathbf{u}$ & 59 & $1 \mathrm{hr}-17 \mathrm{y}$ & $77-.0007$ & .03 & .97 & .95 & $.22(1.4)$ & .97 & .96 & .97 & .97 \\
\hline 1 & $\mathbf{u}$ & 58 & $1 \mathrm{hr}-15 \mathrm{y}$ & $1.9-.0001$ & .09 & .89 & .59 & $.40(.06)$ & .97 & .98 & & .99 \\
\hline 2 & u & 48 & $1 \mathrm{hr}-12 \mathrm{y}$ & $.71-.0002$ & .04 & .93 & .86 & $.45(.03)$ & .95 & .90 & .96 & .96 \\
\hline \multicolumn{13}{|l|}{ Rubin et al. (1986) } \\
\hline $\mathrm{t}$ & $\mathbf{u}$ & 10 & $37 \mathrm{hr}-13 \mathrm{y}$ & $.35-.0002$ & .07 & 1.0 & .17 & $.46(.03)$ & 1.0 & 1.0 & 1.0 & 1.0 \\
\hline s & o & 10 & $37 \mathrm{hr}-13 \mathrm{y}$ & $.19-.0001$ & .07 & 1.0 & .99 & $.44(.01)$ & 1.0 & .99 & 1.0 & 1.0 \\
\hline$M$ & & & & & .06 & .96 & .71 & .39 & .98 & .96 & .96 & .98 \\
\hline
\end{tabular}

Note. The task was always providing autobiographical memories to cue words. $\mathrm{P}=$ participants; $\mathrm{RI}=$ number of points fit; Lin $=$ linear; $\mathrm{Hyp}=$ hyperbolic; $\operatorname{Exp}=$ exponential; $\mathrm{Iog}=$ logarithmic; $m=$ slope parameter; $\mathrm{Pwr}=$ power; $\mathrm{EP}=$ exponential power; $\mathrm{HP}=$ hyperbolic power; $\mathrm{Hi}=$ the highest of the 105 functions fit; $o=$ older adults; $\mathbf{u}=$ undergraduates; $y=$ years.

${ }^{a}$ Subentries are the number of the figure or table in the study from which the data were extracted. If more than one data set was taken, a one- or twoletter code was added to distinguish them from each other. 


\section{Exponential}

Perhaps the most commonly used retention function is $y=$ $b \cdot e^{-m t}$, where $e$ is the base for the natural logarithm. The equation is simple, has mathematical properties that make it easy to use in models, and has been successfully fit to many short-term memory experiments (Peterson \& Peterson, 1959; Wickelgren, $1974 \mathrm{a}, 1974 \mathrm{~b}$ ). It is the equation for radioactive decay; loss is proportional to the amount that is left (Simon, 1966). No matter how much time has passed since initial learning, each time an additional $.69 / \mathrm{m}$, or half-life, passes, the amount remembered is cut by half.

\section{Logarithmic}

The function $y=b-m \cdot \ln (t)$, where $\ln$ is the base $e$, or natural, logarithm also needs boundary conditions. At long times the logarithmic function, like the linear function, becomes negative as opposed to reaching an asymptote at $y=0$. Because the $\ln (0)$ is undefined, when $t=0$, the value of $y$ is undefined. However, values of zero are never included in the data; "immediate" recall is actually recall after a brief period. Moreover, if ratios of time are what matters for the logarithmic function, as will be argued shortly, then ratios involving zero in the denominator are meaningless and should be excluded on theoretical grounds. The same $t=0$ boundary problem holds for the power function where one solution offered is to change the independent measure so that it also goes to infinity instead of to $100 \%$ (Anderson \& Schooler, 1991 ) by using $d^{\prime}$, or ebbs, or an odds ratio. Although some textbooks and journal articles remark that Ebbinghaus used a logarithmic retention function, as noted, he actually combined the logarithm, hyperbola, and power to form his complex retention function. However, the logarithmic function was favored by several early researchers (see Luh, 1922, for a review) and by Woodworth (1938) as the best simple empirical fit to the half-dozen data sets he plotted, including Ebbinghaus's.

There is an easy way to arrive at the logarithmic function if in psychological terms equal ratios of time, not equal intervals, are important. Assume that the psychological difference between the 3 to 4 ratio of 3 and $4 \mathrm{~s}$ is the same psychological difference as that between 30 and $40 \mathrm{~min}$, or 8 and $24 \mathrm{hr}$, or 3 and 4 decades. On a logarithmic scale these differences are all equal to $\ln (3)-\ln (4)$, or -0.29 , though on a linear scale the differences range for $1 \mathrm{~s}$ to 1 decade (i.e., from $1 \mathrm{~s}$ to $3 \times 10^{8} \mathrm{~s}$ ). The ratio view, which justifies a logarithmic transformation, is also supported by the observation that errors in dating follow Weber's law (Rubin \& Baddeley, 1989), as well as by research leading to measures of distinctiveness based on the logarithmic transformation of temporal and order scales (Helson, 1964; Johnson, 1991; Murdock, 1960). The simplest function to describe retention is the linear function, $y=-m \cdot x+b$. If one uses the logarithm of time, as suggested by the equal ratio observation, instead of time for $x$, this equation becomes the logarithmic equation, $y=-m \cdot \ln (t)+b$.

Thus, according to the logarithmic function, forgetting is linear with the ratio of time not the difference in time as it is in the linear equation; equal ratios of time cause equal amounts of loss in remembering. If there are four times, $t_{1}, t_{2}, t_{3}$, and $t_{4}$, such that $t_{1} / t_{2}=t_{3} / t_{4}$, then the corresponding recalls will follow the equation $y_{1}-y_{2}=y_{3}-y_{4}$. For example, if there is a drop in retention from $90 \%$ to $80 \%$ between 1 and $5 \mathrm{~s}$, then there also should be a drop of $10 \%$ between 10 and 50 years. Using the same rationale, one could say that the exponential is a function for which equal intervals of time result in equal ratios of loss in remembering.

\section{Power Function}

The function $y=b \cdot t^{-m}$, was first suggested as a retention function by Wickelgren in a series of experiments on complex retention functions derived from mathematical models of memory (e.g., Wickelgren, 1974a, 1975a, 1975b) and was not directly compared with a range of other functions until it was used in studies of retention in autobiographical memory (Rubin, 1982). More recent empirical work has also supported the power function (Anderson \& Schooler, 1991; Wixted, 1990; Wixted \& Ebbesen, 1991). It implies that if there are four times, $t_{1}, t_{2}, t_{3}$, and $t_{4}$, such that $t_{1} / t_{2}=t_{3} / t_{4}$, then the corresponding recalls will follow the equation $y_{1} / y_{2}=y_{3} / y_{4}$. In words, equal ratios of time result in equal ratios of recall. The power function provides an excellent empirical fit in at least two major areas of research outside retention. It is the best description of the relationships between the judgment of perceptual magnitude, such as brightness, loudness, or salinity, and their underlying physical dimensions (Stevens, 1975), though the logarithmic function also provides a good fit. It describes the relation between the amount of practice and the time taken to perform a host of tasks (Newell \& Rosenbloom, 1981), though a form of the hyperbolic also provides a good fit (Mazur \& Hastie, 1978).

\section{The Other 100 Functions}

There are an infinite number of less studied two-parameter functions. A commercially available program, TableCurve (1994), includes 105 two-parameter functions. These are formed by letting $y$ equal $z, 1 / z, z^{2}, \sqrt{z}$, and $e^{z}$, where $z$ takes on each of the following 21 expressions: $b+m \cdot t, b+$ $m \cdot t \cdot \ln (t), b+m \cdot t^{1.5}, b+m \cdot t^{2}, b+m \cdot t^{2} \ln (t), b+m \cdot t^{2.5}, b$ $+m \cdot t^{3}, b+m \cdot e^{t}, b+m \cdot t^{\cdot 5} \ln (t), b+m \cdot[\ln (t)]^{2}, b+m \cdot t /$ $\ln (t), b+m \cdot t^{5}, b+m \cdot \ln (t), b+m / \ln (t), b+m \cdot t^{-5}, b+$ $m \cdot \ln (t) / t, b+m / t, b+m \cdot t^{-1.5}, b+m \cdot \ln (t) \cdot t^{-2}, b+m \cdot t^{-2}$, and $b+m \cdot e^{-t}$. Although not exhaustive, these 105 functions, which include the five classic ones, provided a reasonable initial search set and one that was chosen without awareness of the purposes of this project.

We limited the search to two-parameter functions, although theoretically motivated three-parameter functions exist (e.g., Indow, 1993; Wickelgren, 1974a) and other functions with three or more parameters could be formulated. We did this first because the large number of reasonable functions with three or more parameters would have greatly expanded the scope of our initial search to the point where it would have become unwieldy. Second, comparisons among functions of different numbers of parameters are difficult because functions with three or more parameters usually fit better than two-parameter functions. Third, differentiating among functions with three or more parameters should have data sets with more points than many of 
the ones included here. Fourth, most recent debate has centered on two-parameter functions. Nonetheless, a function with three or more parameters could be the best theoretical function, especially if the parameters could be identified with concepts in the theory or if they varied systematically across experimental conditions, such as amount of initial learning or the dependent measure of remembering. Our decision was to postpone such an expanded search until the two-parameter functions could be evaluated to see whether any obvious addition of parameters, such as in Wickelgren's ( 1974a) function that multiplies an exponential and a power function factor, would provide more explanatory power for the data. Nonetheless, it could be argued that the problem of retention is complex enough to warrant at least three parameters. One parameter is needed for the level of initial learning. One parameter is needed to scale the time range of the experiment. Finally, a third parameter is needed to say something about the shape of the function and how it changes with conditions.

\section{Basic Results}

\section{Determining the Best Fitting Functions}

In fitting many functions to many data sets, the first check that has to be made is whether the results can be accounted for by a random process. Figure 3 is a histogram. Each of the 105 functions appears as one point. The number of data sets, out of a possible 210 data sets, in which each function was among the best fitting 10 functions is given by the values on the left axis. The classic five retention functions and some other successful equations are given at the right of the histogram. The most successful function by this ranking measure is the logarithmic, which appears as one of the best 10 functions in 109 of 210 data sets.

The number of times a function should be in the top 10 by chance is $(10 / 105) \times 210$, or 20 . The standard deviation of such a binomial distribution is $(n p q)^{.5}$, or $[(210)(10 /$ $105)(95 / 105)]^{.5}$, which equals 4.25 . If the distribution shown in Figure 3 were the result of random processes, it would be symmetrical around a mean of approximately 20 . It is not. Rather, Figure 3 shows that there are a few functions that are successful by the ranking measure but that most functions are not. The successful functions are not just one tail of a binomial distribution but are outliers.

Several functions appear among the most successful that have not been considered by psychologists. One, $y=[b-m \cdot \ln (t)]^{2}$, is the logarithmic function squared. When expanded it becomes $y=b^{2}-m \cdot b \cdot \ln (\mathbf{t})+m^{2} \cdot \ln (t)^{2}$. If $m$ is smaller than $b$ (it is in most fits by about a factor of 10 ), the $m^{2}$ term may be small enough to be ignored, and the equation could be rewritten as $y$ $=b^{\prime}-m^{\prime} \cdot \ln (t)$, where $b^{\prime}=b^{2}$ and $m^{\prime}=m \cdot b$. That is, if $m$ is small enough, the equation approximates the logarithmic equation. Both equations appear together or are absent together from the best fitting 10 equations in 180 of the 210 data sets. In the remaining 30 data sets in which one function is in the top 10 and the other is not, the equation that is not appears in the top twenty 25 times and in the top thirty 4 times. Moreover, the $b^{\prime}$ $=b^{2}$ and $m^{\prime}=m \cdot b$ equations were good approximations for the data sets examined. Thus, if the logarithmic equation fits, $y=$

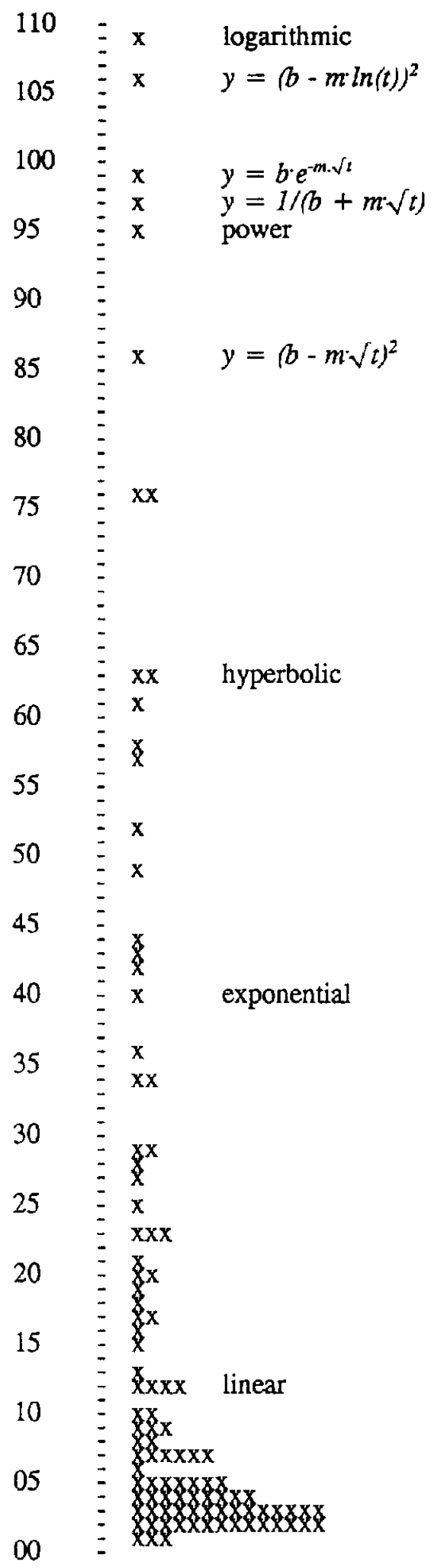

Figure 3. A histogram showing the number of times each of 105 functions was one of the best 10 fits to the 210 data sets. Each mark represents one function. The commonly used five functions are labeled verbally, other successful functions are labeled with their formulas. The maximum possible value is 210 . chance is $20(S D=4.25)$. 
$[b-m \cdot \ln (t)]^{2}$ also fits with a similar intercept and slope and so is considered a more complex form of the logarithmic equation. In addition, for very long times, the value of $y$ will increase with time for this equation. For these reasons the equation is not pursued further. However, if theoretically motivated, it could be used in place of the logarithmic equation.

Many of the other novel functions come from the five equations based on the expression $b+m \cdot \sqrt{t}$. The success of so many functions based on the square root of time was a surprise. However, it should be noted that the square root was the only power less than 1 included in the 105 functions tested, and so its success does not argue for its superiority over other fractional powers of time and suggests that such powers should be investigated further. The two most successful square-root-of-time functions are $y=b \cdot e^{-m \sqrt{t}}$ and $y=1 /(b+m \cdot \sqrt{t})$. These two equations can be seen as the standard exponential and hyperbolic equations with the square root of time substituted for $t$. They therefore have well-defined intercepts of $b$ and $1 / b$ at $t=$ 0 and asymptote to 0 at long times. The third most successful function, which fits approximately as well as the power function, is $y=(b-m \cdot \sqrt{t})^{2}$. When expanded to $y=b^{2}+m^{2} t-$ $m b \cdot \sqrt{t}$, the equation looks like the standard linear equation with an added $\sqrt{t}$ term, but it is not in that the coefficient of $t$ is positive. The function decreases smoothly for a while but then starts to increase and does so at a much faster rate than the quadratic equation in $\ln (t)$ discussed earlier. Because of this property and because the function adds little empirically to the other functions in $\sqrt{t}$, it is not considered further.

It was suggested that the best fitting functions may just be the most flexible ones, the ones most able to change their basic shapes to fit any data sets by changing their parameters. This concern is not a problem for the best fitting functions found here. First, all functions tested have only two parameters limiting their flexibility. Second, each can be transformed into a straight line by one particular combination of transforming the $y$ axis to $y, \ln (y)$, or $1 / y$ and the $x$ axis to $t, \ln (t)$, or $\sqrt{t}$. In these transformed versions, it can be seen that there is little flexibility available to change the basic shape of the functions; the two free parameters determine the slope and the intercept of a straight line.

\section{How Well Do the Same Functions Fit All Data Sets?}

The top-10 measure, more commonly used to quantify popularity in music, is sufficient to show that some of the 105 functions tested often worked well whereas others rarely did, but it is not the best way to compare fits. Tables 1 to 9 contain the fit of all 210 data sets to the five classic functions and the two nonclassic best fitting functions just discussed, the exponential and hyperbolic in $\sqrt{t}$, using $r^{2}$ as measure of amount of variance accounted for for each function. The rightmost column contains the highest $r^{2}$ obtained with any of the 105 functions. It therefore can be viewed as an approximate upper bound of what could be expected from a wide range of two-parameter functions. At the end of Tables 1 to 9 are rows for the average $r^{2}$ values of each function. The histogram was based on fits chosen by the program that resulted in approximations for the hyperbolic and two functions in the square root of $t$. Here slower iterative solutions were used for these functions, which resulted in an occasional increase in their $r^{2}$ values.

Table 10 is a summary that averages the values of the fits from Tables 1 to 9 . In addition we present the same summary but from calculations of linear fits to transformations of the data. We do this to provide a comparison to the most commonly used

Table 10

Summary of Tables 1 to 9

\begin{tabular}{|c|c|c|c|c|c|c|c|c|c|}
\hline \multicolumn{2}{|r|}{ Source } & \multicolumn{8}{|c|}{$r^{2}$ ft of selected functions } \\
\hline Table & Description & Lin & Hyp & Exp & $\log$ & Pwr & EP & HP & $\mathrm{Hi}$ \\
\hline \multicolumn{10}{|c|}{ Average of data sets reported in tables $1-9$} \\
\hline $1-9$ & Grand mean & .68 & .83 & .79 & .86 & .86 & .87 & .88 & .95 \\
\hline $1-8$ & Grand mean, without Table $9^{a}$ & .69 & .83 & .79 & .87 & .86 & .87 & .88 & .95 \\
\hline \multicolumn{10}{|c|}{ Average of data sets using tranformed dependent measures } \\
\hline 1 & Bahrick & .50 & .61 & .57 & .84 & .73 & .71 & .69 & \\
\hline 2 & Wickelgren & .68 & .84 & .78 & .88 & .88 & .87 & .88 & \\
\hline 3 & Recognition & .73 & .81 & .78 & .87 & .83 & .86 & .86 & \\
\hline 4 & Recall & .71 & .82 & .80 & .89 & .86 & .88 & .84 & \\
\hline 5 & Savings/relearning & .56 & .73 & .66 & .89 & .88 & .81 & .84 & \\
\hline 6 & Sensorimotor & .74 & .79 & .77 & .92 & .84 & .87 & .82 & \\
\hline 7 & Animal & .82 & .86 & .84 & .87 & .85 & .89 & .89 & \\
\hline 8 & Miscellaneous & .73 & .75 & .76 & .83 & .81 & .82 & .79 & \\
\hline 9 & Autobiographical memory & .06 & .86 & .52 & .39 & .97 & .73 & .82 & \\
\hline $1-9$ & Grand mean & .68 & .80 & .76 & .86 & .84 & .84 & .83 & \\
\hline $1-8$ & Grand mean, without Table $9^{a}$ & .70 & .79 & .76 & .87 & .84 & .85 & .83 & \\
\hline
\end{tabular}

Note. $\quad$ Lin $=$ linear $;$ Hyp $=$ hyperbolic $;$ Exp $=$ exponential $;$ Log $=$ logarithmic $; \mathrm{Pwr}=$ power $; \mathrm{EP}=\operatorname{expo-}$ nential power; $\mathrm{HP}=$ hyperbolic power; $\mathrm{Hi}=$ the highest of the 105 functions fit to the untransformed data. ${ }^{a}$ Because the autobiographical memory data sets differ from the other data sets, we also provide means without them. 
method in the literature. The basic conclusions remain the same, but the nonlinear fits to the untransformed data do provide slightly higher $r^{2}$ values (about .02 higher on the average). The difference, however, can sometimes be large, especially for the hyperbolic and hyperbolic in $\sqrt{t}$.

One of the biggest surprises from Figure 3 and Tables 1 to 9 was how well the same functions fit different data sets. The tables have a restricted range of $r^{2}$ values because they contain the five classic functions, most of which were good predictors in the past, and two added functions chosen for their fit. Nonetheless, although there are exceptions, the same functions fit most data sets. One way to describe the degree of similarity is to consider the five classic functions, eliminating for the moment the two that were included in the tables based on the same data that are to be examined. The overall rank order of most to least variance-accounted-for measure given in Table 10 is the same as measure of the number of data sets fit in the top 10 functions in Figure 3: logarithmic, power, hyperbolic, exponential, and linear. Except for the autobiographical memory data, this rank order occurs in all of the tables, with minimal exceptions. In particular, the logarithmic and power functions are inverted in Wickelgren's and the savings data, the power and hyperbolic functions are inverted in the recall and animal data, the exponential and linear functions are inverted in the sensorimotor data, and the hyperbolic and exponential functions are inverted in the miscellaneous data. Considering that most of these differences would not be statistically significant, the stability is notable.

The exponential and hyperbolic in the square root of time fit consistently well, occurring as two of the best fitting four functions in Tables 1 to 9 . Their exact ordering is less consistent, with both sometimes doing better than the five classic functions (as in the overall means, recall, and animal studies data), sometimes between the best and second best of the classic five functions ( as in the sensorimotor, miscellaneous, and autobiographical memory data), and sometimes with one of the square-root functions being the best and the other third or fourth best (as in the Bahrick, Wickelgren, and recognition data).

\section{Autobiographical Memory}

The autobiographical memory data sets are clearly different from the other data sets, but there is also clear agreement among them indicating that this difference is not by chance. As noted in Rubin (1982), the power function is the best fitting of the classic five functions, accounting for $97 \%$ of the variance, whereas the logarithmic function accounts for only $39 \%$. We therefore separate the autobiographical memory data sets from the rest. The autobiographical memory procedure is different from that in most other experiments in that no particular memory is required; the participants can produce any memory they want from their lives. Thus, autobiographical memory involves much more sampling from among memories and is more subject to the ease of availability than other procedures (Rubin, 1982; Rubin, Wetzler, \& Nebes, 1986).

One possible reason for the difference is that the extreme range of times, typically from $1 \mathrm{hr}$ to 18 years, is causing the difference. To see whether this can be the case, the five autobiographical memory data sets were divided into two time in- tervals. The first approximated a typical laboratory study that had $1 \mathrm{hr}$ as its shortest interval by including all data up to 1 week. A second interval, which was more like that used by Bahrick, included times from beyond 1 week to 20 years. The transformed versions of the hyperbolic, exponential, and power functions were used for these analyses so that an exact fit could be obtained without iterations. For the two Rubin et al. (1986) data sets, this meant that there were only two points in the short interval and only the long interval could be used. For the other three data sets, both the short and long intervals had a minimum of 22 points, except the Rubin (1982) data set, which had seven points in the short interval. Although the values for amount of variance accounted for the power function decreased from $97 \%$ to $85 \%$ and $88 \%$ for the short and long intervals when the data sets were divided and increased for the logarithmic function from $39 \%$ to $57 \%$ and $65 \%$, the superiority of the power function remained substantial. The differences observed in the autobiographical memory data sets cannot be attributed to just an artifact of their large range of retention intervals.

Another technical reason for differences between the autobiographical memory data sets and the others is the range of the dependent variable. In most data sets considered here, the range is about one order of magnitude, but for the autobiographical memory data sets it is three or four orders of magnitude. Three of the autobiographical memory data sets had enough points to be divided: Crovitz and Schiffman (1974, Experiment 1), Rubin (1982, Experiment 1), and Rubin (1982, Experiment 2). Two were each divided into four data sets, with a range of one order of magnitude in their dependent variable. The third, $\mathrm{Ru}$ bin (1982, Experiment 2), was divided into three data sets because it had only one value that was beyond a range of three orders of magnitude. With these divisions, which are smaller than those just used to investigate the time-range problem, the superiority of the power function compared with the logarithmic shrunk dramatically. Averaging over the 11 data sets with a single order of magnitude, the power accounts for $76 \%$ of the variance; the logarithmic, 70\%; the hyperbolic, 70\%; the exponential, $66 \%$; and the linear, $50 \%$. When the three source data sets are not divided, these average figures for amount of variance accounted for are $96 \%, 36 \%, 84 \%, 58 \%$, and $5 \%$. Thus it is possible that the differences noted in the autobiographical memory data sets are caused by the expanded range of their dependent variable.

If the range explanation holds then, in an ideal world where reliable values of percentage remembered in laboratory tasks could be extended from $99 \%$ down three orders of magnitude to $0.1 \%$, the power function also might provide a much better fit than the logarithmic for laboratory learning. Data on this issue are lacking, and so two possibilities remain. One is that the retention function of autobiographical memory is different from that of laboratory tasks. This possibility is supported by the power function's consistent, though reduced, superiority over the logarithmic function in all analyses. The second is that the retention function of autobiographical memory is the same as that of laboratory tasks, but that laboratory studies to date have only tapped a small section of their range that is better fit by logarithmic and other functions than the whole range would be. 


\section{Other Issues}

The data sets that used savings as a dependent measure also differ from the others, but less dramatically than the autobiographical memory data sets. Luh had a similar conclusion. He found recognition, reconstruction (serial ordering), recall, and anticipation all had parallel plots, but that "relearning does not satisfy quite the same type of equation as the other memory processes"'(1922, p. 28 ).

Another minor exception to the general pattern occurred in the animal studies. Here the relative order of success in terms of rank was roughly the same as in other tables, but there was little variability in how well each of the individual five classic functions fit, with the best accounting for $87 \%$ of the variance and the worst, $82 \%$. The small difference in fits could be due to difference in the stimuli, the general procedures (which in most cases resulted in six or fewer retention intervals), the species, the range of times (which with two exceptions had their longest retention interval less than $45 \mathrm{~s}$ ), or the percentage recalled values (which because of the methods used were rarely below $50 \%$ ). In any case, a replication of the animal studies, changing the species to humans and using stimuli that are difficult to label, might be one first step to investigate this difference.

The power function has recently been argued to be the best retention function (Anderson, 1990, 1995; Anderson \& Schooler, 1991; Rubin, 1982; Wixted \& Ebbesen, 1991). The superiority of the logarithmic function, as foretold by Woodworth (1938), is therefore a challenge that requires further investigation. If the $r^{2}$ values of the 205 nonautobiographical memory data sets of Tables 1 to 8 are compared, with each data set being considered as an independent observation, then the logarithmic function is a better fit than the power function, $t(204)=3.20$, accounting for $1.5 \%$ more of the variance. The logarithmic function does even better if the normally used linear fit to transformed data is applied, $t(204)=5.68$, accounting for $3.2 \%$ more of the variance. Such differences may not be enough to draw a clear conclusion, but they are enough to say that the power is not a better fit for the percentage correct measure.

\section{Slopes}

In Tables 1 to 9 we give the slopes for the logarithmic function. We choose this function because it is the best fitting of the common five functions and because it has two useful properties. First, the slope does not depend on the units of measurement of time. Thus all studies using the same dependent measure, such as percentage recalled or $d^{\prime}$, can be directly compared. Second, the dependent measure does not have to be transformed to use a linear fit, and thus the type of fit previously used in the literature was used here. The slope values allow the rate of loss among conditions in one study to be contrasted, and if caution is used, trends across studies can be made, though comparisons of studies that use different dependent measures are not meaningful. The values given also serve to demonstrate in a concrete fashion the seriousness of our concern that a function needs to be chosen before questions about rate of loss can be raised.

Consider two studies that claim that slopes do not change with the age of the participant. Using a modified power func- tion, $y=b(1+.22 \cdot t)^{-m}$, Wickelgren (1975a) found slopes of $.26, .26$, and .24 for children, adults, and older adults, respectively, whereas we found corresponding slopes of $.09, .28$, and .18 with the logarithmic function. Rubin et al. (1986), using a power function, found slopes of .93 and .96 for 20 - and 70-yearolds, whereas here we found slopes of .03 and .01 with the logarithmic function. If the pattern of results of slopes with the logarithmic function is examined in these studies and in the two other developmental studies (Fajnsztejn-Pollack, 1973; Schonfield, 1969, as cited in Kausler, 1982), it is clear that the logarithmic function gives a steeper slope when the level of initial learning is higher, independent of the age of the participant. In agreement with Slamecka and McElree (1983), under either analysis there is no evidence of less loss with increases in the initial learning level. However, there is a consistent trend to more loss with increased initial learning level if the slope is calculated from the logarithmic function.

The point of this analysis is that conclusions drawn about rate of loss depend in dramatic ways on the function used to describe retention. The concern of those involved in the debate reviewed earlier on how to measure retention and to decide whether loss is different for different degrees of initial learning is warranted. Questions about rate of loss can be answered only in the context of a particular retention function (Wixted, 1990). Alternatively, one could choose the retention function to make the slopes behave in a desired fashion. Thus the power function could be favored over the logarithmic, because the rate of loss does not change with age even when the level of initial learning does (Anderson \& Schooler, 1991). Because of the dependence of interpretations of slope values on the function generating the slope, further interpretations should await a decision about a function.

\section{Theoretical Motivations for the Exponential and Hyperbolic-Power Functions}

\section{General Properties}

Having described and summarized the basic quantitative findings, now is the time to consider a theory, or competing theories, that could account for them. As the logarithmic and power functions have been described earlier, we concentrate on the exponential in $\sqrt{t}$ and the hyperbolic in $\sqrt{t}$. When the .5 power of the square root is replaced by the parameter $c$, these become

$$
y=b \cdot e^{-m \cdot t^{c}} \text { and } y=1 /\left(b+m \cdot t^{c}\right) .
$$

The first equation was called the exponential-power function by Wickelgren (1972), and by extension we call the second the hyperbolic-power function. Alternative forms exist for both functions. Replacing $m$ by $(1 / T)^{c}$ changes these functions into

$$
y=b \cdot e^{-(t / T)^{c}} \text { and } y=1 /\left[b+(t / T)^{c}\right] .
$$

For the exponential power when $t=0, y=b$ and when $t=T, y$ $=b / e$. For the hyperbolic power when $t=0, y=1 / b$ and when $t=T, y=1 /(b+1)$. At all other values of $t, y$ is a function of $c$. Thus both functions have clear intercepts $(b$ and $1 / b$, respectively) and both have a parameter $T$ that is related to their 
slopes, because when $t$ goes from 0 to $T$, the functions drop a set amount, $b(e-1) / e=.63 b$ and $1 / b(b+1)$, respectively. For both functions, the $c$ parameter indicates the degree of curvature of the function.

In searching for regularities, we limited ourselves to two-parameter functions and found two such functions that are actually three-parameter functions with one parameter set to .5. An attempt was made to allow the exponent $c$ in the exponentialpower and hyperbolic-power functions to vary from .5 , changing the two-parameter function into a three-parameter function. With the data sets assembled, we reached the same conclusion that Wickelgren (1972) did over two decades earlier. No clear pattern emerged. One reason was that most data sets had too few points to allow three-parameter functions to be easily distinguished. A second reason was that the functions themselves do not differ dramatically over the range of $c$ from .1 to .9 that we examined. There is some trend, which was clearer in the data sets with more points, for powers of less than .5 to fit better for the exponential-power function. However, given the data available, we leave the powers fixed at .5 .

\section{The Exponential-Power Function}

Before examining theoretical motivations for the exponential-power function, its simpler mathematical properties need to be noted. Assume for the rest of the paragraph that the values of $b$ and $T$ remain constant. When $c=1$, the exponential power is the exponential. Graphing the functions shows that with powers greater than 1, it is an S-shaped function that stays near its initial level for a while and then drops sharply before leveling. The larger the value of $c$, the more the function looks like a step function, remaining above the exponential for $t<T$ and below the exponential for $t>T$. For powers less than 1 , like the square root, the function begins by dropping faster than the exponential until $t=T$ but then drops more slowly and remains above the exponential. Palmer and Stein (1989a, 1989b) noted that with $c<1$ for large values of $t$, the function drops faster than the power or logarithmic functions.

The exponential-power function was first derived as a retention function by Wickelgren (1972). He derived the three-parameter function for long-term memory from the following three axioms: (a) The rate of change of strength of the trace with respect to time is equal to -1 multiplied by the force of decay acting on the trace divided by the resistance of the trace; (b) the force of decay is proportional to the similarity of the material currently being studied multiplied by the strength of the trace; and (c) the resistance is equal to a positive constant multiplied by time raised to a power between 0 and 1 . The axioms were supported by brief reviews of retrograde amnesia and interference theory. The set of three axioms is interesting, especially the axiom that the resistance of memories increases with time, but they are not well supported in their quantitative form. Although Wickelgren derived a three-parameter function, he analyzed his data with a two-parameter function by using the special case of $c=.5$, apparently because the square root was the simplest value of $c$ between .4 and .8 , which is where the best empirical fits occurred (pp. 419-420). Thus, the finding that $y=b \cdot e^{m \sqrt{t}}$ fits a wide range of data offers support for Wickelgren's theory, although he abandoned the function in fa- vor of others derived from different axioms. Besides Wickelgren's theoretical mechanisms, other possible motivations for the exponential power exist because of the function's long and distinguished history outside psychology.

The exponential-power function was first used by Kohlrausch in 1854 to describe the decay of a static-electric charge in a Leyden jar (Bendler \& Shlesinger, 1987). The exponential power has since been used in many different fields, where it goes by many names, including the extreme value distribution, the fractional exponential, the Kohlrausch-Williams-Watts law, the stretched exponential, the third asymptotic distribution, and the cumulative Weibull distribution. For an example Banks (1994) used it to describe a problem in technology transfer: the rate at which diesel and electric locomotives replaced steam locomotives in the United States. Gumbel (1958) applied the distribution to account for extreme values distributions, such as in analyzing droughts on the Colorado and Connecticut Rivers. Earlier applications by Weibull (1951) were for the study of dynamic breaking strength in materials and machines (i.e., how long material lasts until failure). Palmer and Stein (1989a, $1989 \mathrm{~b}$ ) used the function to describe the slow relaxation of materials after a step-function stress is applied. In this guise, values of $c$ between .5 and .7 are common for glasses and values of .3 for polymers. It has also been used to describe creep in rubber fibers, dielectric relaxation, return to randomness after nuclear magnetic resonance, and optical scattering (Bendler \& Shlesinger, 1987). As Weibull (1951, p. 293) noted, "lt is utterly hopeless to expect a theoretical basis for distribution functions for random variables such as strength properties of materials or machine parts or particle sizes, the 'particles' being fly ash, Cyrtoideae, or even adult males, born in the British Isles." Nonetheless, a function with so many varied applications might have a derivation or mechanical analog that could be adapted for a theory of retention.

Weibull's ( 1951 ) derivation of the exponential power is based on the model of a chain made of $n$ links, where $n$ is large. If any one link breaks, the chain fails. If the probability that a link will break by time $t$ is $p$, then the probability that it will not break by time $t$ is $(1-p)$, and the probability that none of the $n$ links will break is $(1-p)^{n}$. By starting in this way and choosing a distribution function for the individual links that happens to yield the correct result, the exponential-power function is obtained. Cox (1962, pp. 109-110), starting with the same ( 1 $p)^{n}$ idea and different distributions, arrived at the same answer. Indow (1993) used the weakest-link chain idea to produce a model of retention by assuming that if any one feature of a memory trace changed, then with the cues available the memory would not be accessed.

Analogs for memory also follow from two different models of the study of the relaxation of glassy materials. In the first formulation, Bendler and Shlesinger (1987) assumed a threedimensional lattice of polarizable glassy material made of individual dipole moments. At $t=0$ the field is turned off and the frozen-in dipoles start to relax. The average correlation of their current position with their position when the field was on decays by the exponential-power law. Frozen-in dipoles relax when they are contacted by a mobile defect. The defects are scattered throughout the lattice and move independently and randomly with time, but activation barriers with a distribution of heights 


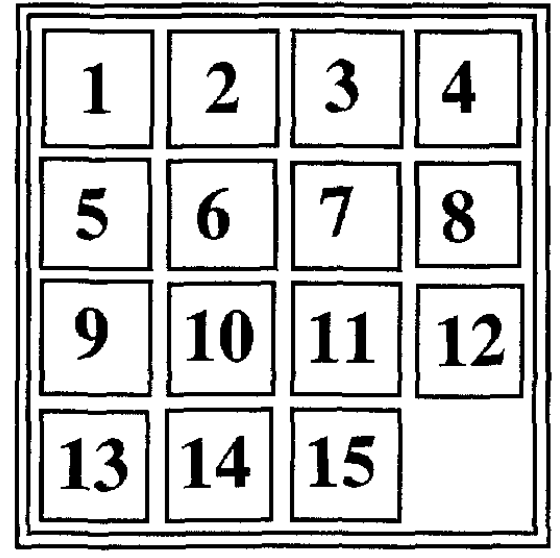

Figure 4. A toy model adapted from Palmer and Stein (1989b). The restricted moves of the toy lead to a loss of information in the position of the pieces that approximate the exponential-power function.

must be jumped for the defects to move. With the proper choice of the distribution of barrier heights, the desired equation is reached. Moreover, if both shallow dipole traps and frozen-in dipoles are considered, the distribution starts out as exponential and then changes to exponential power. If one envisions memories, or aspects or features of memories, as being distributed in an abstract space with random noise spreading through the space and changing values of the memories they contact, such a mechanism could be adapted for memory. Bendler and Shlesinger's model will not be pursued because the second glassymaterial formulation seems easier to apply.

The second model of glassy material relaxation does not use defects or barriers. The model is for relaxation following mechanical stress, temperature, electric field, or some other step function change. Instead of barriers to impede the random movement, paths are removed to produce constrained dynamics. Before tackling this more abstract formalism directly, consider what is technically termed in the physics of complex systems a toy model, which in this case is the toy shown in Figure 4. Palmer and Stein ( $1989 \mathrm{~b}$ ) noted that many models with constrained dynamics produced the exponential-power function, so they tried a relatively simple two-dimensional model. The standard toy shown in Figure 4 has an area of $L^{2}$ squares, of which $L^{2}-1$ are filled. As anyone who has tried the puzzle knows, the paths that can be taken by a labeled square are limited, and moving a labeled square from a particular location to another requires other squares to be moved opening a path, slowing the movement of all squares in the puzzle. If glass were deformed, molecules might not be able to relax to a lower energy position until neighboring molecules moved. In simulations, which produced the exponential-power function, the open square was allowed to move randomly, $L$ was much larger than 4 , and the measure of the amount of decay was the city block distance between the original and current locations of each square. Equilibrium, which would be analogous to no memory, would occur when this distance no longer systematically increased because all information of the original position was lost.

A more general form of this class of models is the diluted hypercube. An $N$-dimensional hypercube has $2^{N}$ points or states and $N \cdot 2^{N} / 2$ edges. The state of the system is defined by the $N$ tuple of ones and zeros defining the location of a marker. The marker moves randomly along the edges of the hypercube, but in the diluted hypercube most edges have been removed, making transition from one state to another slower, as in the puzzle analog. Again, under many conditions, the ability to predict the current position from the original position follows the exponential-power function. In many instances, the exponent tends toward $1 / 3$. If one were to consider memories as $n$-tuples of zeros and ones, or equivalently ones and minus ones, and were to degrade them by randomly changing the sign of one feature every $t$ seconds, one could build a model of memory (e.g., Hintzman, 1986). It may be possible in such a model to incorporate the constrained dynamics idea by generating such random changes but acting on only those that occur along existing edges of the hypercube. Alternatively, the states of the system could be limited instead of the edges ( Palmer \& Stein, 1989b). For a model like Hintzman's, retention would be calculated from an average of all stored traces.

In a model of memory the paths or states could be limited to those that really exist as entities in the world, which need not be true of every combination of features a random change of sign might produce (Rubin \& Wallace, 1989). Similar mechanisms might be able to produce appropriate retention functions within the framework of other models of memory. The reason retention would show an exponential-power function is that the dynamics of loss are constrained. A greater movement from the original "location" could still be remembered as the original position if better or broader cuing were used.

\section{The Hyperbolic-Power Function}

Having provided theoretical frameworks for the logarithmic, power, and exponential-power function, none could be found for the hyperbolic-power function. Nonetheless, its simpler mathematical properties can be noted. Assume for the rest of the paragraph that the values of $b$ and $T$ remain constant. When $c=1$, the hyperbolic power is the hyperbolic. With powers of less than one, a parallel situation exists to that in the exponential power. The function begins by dropping faster than the hyperbolic until $t=T$, where it would cross the standard hyperbolic, but then it drops more slowly and remains above it. With powers of greater than one, the opposite is true.

\section{Three Omissions}

\section{A Study of Prediction}

How well one can predict future forgetting? For instance, if one knows that a group of students studied a lesson until they just knew it perfectly and that $1 \mathrm{hr}$ later they remembered $80 \%$, can more be said about remembering 1 week later than it will be between 0 and $80 \%$ most of the time? How much would another test at 1 day add to our ability to predict? If we had the immediate and 1-day test and could add a third test between them, when should it be given to most improve our prediction? How much would be gained by a well-placed fourth or fifth test? The answers will depend on the function chosen, and the ones 
that produce the best fits may not produce the best extrapolations over long gaps.

A comprehensive way to begin would be to see how the best fitting parameters for the best fitting functions change as we remove data points from each data set, starting with those for the longest retention intervals and moving sequentially toward the most recent. To the extent that the parameters do not change, the extrapolation would be as good as the interpolated curve fitting. If systematic changes occur in the parameters, they could be compensated for, thereby reducing the error. The same procedure could be used to see what range and spacing of short retention-interval points are most useful in predicting the longest retention-interval points (see Baron \& Cerella, 1993, for a similar logic applied to acquisition ).

If the data fell perfectly on a known function, none of this would be necessary. Once $n$ of the points were known, a curve with $n$ free parameters could be fit and would make perfect predictions. However, with less than perfectly fitting functions and with noisy data, having an estimate of how accurate prediction is given known variability in the data, a given number and placement of points, and the gap in time between them and the tobe-predicted retention interval would be of practical interest. At the least, it would allow us as experimental psychologists to offer advice on estimating loss of knowledge with time and to know how good that advice is.

\section{A Study Contrasting Dependent Measures}

With minor exceptions, we report data in the units used by the original authors. But for most theories, one specific measure is best. For instance, to test Anderson's (1990) claims, we should use the odds ratio. For theories that assume that memory strength is continuous and that remembering is a matter of whether a threshold in that strength is reached, $d^{\prime}$, ebbs, or other mcasure of underlying strength would be more appropriate. Including all such measures here would have greatly expanded already lengthy analyses. An efficient way to test several theories that use different dependent measures would be to keep one dependent measure and transform the retention functions to be tested. Thus, instead of testing the power function against oddsratio-transformed data, one could keep the percent-recalled data and transform the power function to $\left(b \cdot t^{-m}\right) /\left(1+b \cdot t^{-m}\right)$ (J. R. Anderson, personal communication, November 1994).

\section{A Study Discriminating the Best Fitting Functions}

There are no existing data sets that can distinguish among the best fitting functions. The following six criteria would define such a data set.

1. There should be nine or more retention intervals, which would allow nonlinear iterative fits of functions with two or three parameters to be made and discriminated.

2. The study should have small confidence intervals for each of these retention intervals, which should be publicly reported with the means (Loftus, 1993). Functions that do not remain within the obtained confidence intervals could be rejected. In the existing literature, confidence intervals are rarely reported, cannot be calculated from reported statistics in most procedures, and when they can they are too large to reject functions.
The study need not have the same number of observations at each retention interval, but rather should obtain near-equal confidence intervals at each retention interval. If a measure such as $d^{\prime}$, odds ratio, or ebbs was the main measure, the nearequal confidence intervals should be in terms of this measure.

3. To distinguish among the four most successful functions, which are based on logarithmic (or logarithmic-like) scales, the study should have a large ratio of the most to least amount remembered and a large ratio of the longest to shortest retention intervals without obtaining indeterminate amount-recalled values of $0 \%$ or $100 \%$. Except for the autobiographical memory studies, the dependent measure in existing studies of retention usually ranges over a ratio of less than 10 to 1 . This ratio could be expanded to a ratio of 90 to 1 . The analysis of the autobiographical memory data sets suggested that increasing the range of values of the dependent measure may allow the logarithmic and power functions, in particular, to be more easily distinguished.

4. For the time between presentation and testing to be unambiguous, each item should be presented only once, but if multiple presentations are used, they should be spaced close together compared with the shortest retention interval in order to keep the length of the retention intervals well defined.

5. The activity that fills the retention intervals should be constant throughout the experiment so that time is proportional to the amount of intervening material.

6. Ideal data would allow retention functions (with larger confidence intervals) to be plotted for individual participants to guard against attributing to the aggregate data a retention function that does not describe individuals.

One method to meet these requirements would be a generalization of Wickelgren's continuous recognition procedure (Wickelgren, 1972, 1974a) adapted to cued recall, recognition, and implicit memory. The method produced relatively smooth curves for Wickelgren, even when he used only six participants. Because over the course of the experiment each participant is tested at each retention interval, it would be possible to obtain fits for each participant individually. To test whether this kind of procedure could distinguish among the four best fitting functions, we assumed that one of them-the logarithmic function-was correct, and we generated ideal data from it. With nine points spread evenly on a logarithmic time scale, we could reject the other three functions if the confidence intervals on the data points were $\pm 2 \%$. Thus, from a data set that meets the six properties described, it would be possible to distinguish among our top four functions or possibly to reject all four and have enough data points to distinguish among alternative three-parameter functions. From a set of such data sets, it would also be possible to test whether one function could hold over a range of tasks. In addition, it would be useful to have a comparison within one experiment between conditions that presented and tested each item only once and conditions that presented items more than once at carefully chosen intervals. In the literature, the dimension of whether items are presented once or many times is not salient, yet the distinction is central to building a model of memory in which each presentation is considered as a separate event. Such a study would by necessity merge the literatures on spaced practice and retention functions. 


\section{Discussion}

\section{An Evaluation of Description Before Theory}

Cognitive and experimental psychology has long been dominated by the inferential-statistics hypothesis-testing approach (Meehl, 1978) that has provided much of the data reviewed. Nevertheless, we argued by example that this approach has hindered the uncovering of theoretically useful and practically important regularities. It has encouraged researchers to formulate and test hypotheses on their own new data rather than to examine existing data. It has also encouraged researchers to ignore the important cases where there are no differences when conditions are changed (Greenwald, 1975; Rubin, 1989). This article demonstrates that psychology can note quantitative regularities that are far more useful than rejected null hypotheses. Although sophisticated mathematical models of memory exist (e.g., Gillund \& Shiffrin, 1984; Hintzman, 1986; Murdock, 1982), they do not make strong predictions about the mathematical form of the retention function. Even Anderson's adaptive model that favors the power function is only committed to the claim that retention and recurrence of events in the environment are similar (Anderson, 1990; Anderson \& Schooler, 1991).

There is a circular problem that our approach has begun to solve. Because no adequate description of the empirical course of retention exists, models of memory cannot be expected to include it. Because no current model predicts a definite form for the retention function, there is no reason for individual model makers to gather retention data to test their models. Here the description of the empirical course of retention was made both for its own sake and as a challenge and impetus to inclusion in model building.

We explicitly considered and rejected an alternative strategy. We could have proposed a theory that explains only the shape of the retention function and attempted to test it. Our findings indicate that progress was much less likely that way for at least two reasons. The first reason is the incompleteness of the set functions that happen to be derived from theoretical principles. No theory we could find posited the hyperbola in the $\sqrt{t}$, even though it turns out to be one of the best fitting retention functions and even though it may have a reasonable derivation and interpretation within an existing model of memory. The second reason is the problem of testing alternative derivations of such a function. Another one of the four best fitting retention functions, the exponential in the $\sqrt{t}$, has at least four totally independent derivations that do not share common underlying mechanisms. Because all four theories or mechanisms arrive at the same function, there is no way for the retention data to distinguish among them.

A more fruitful course is to add to the shape of the retention function to the collection of other observations that mathematical models of memory already attempt to explain. Models that can also account for these other observations are much less likely to be consistent with all mechanisms that can be used to derive a function and thus can be used to eliminate some derivations. Thus the preferred approach is to provide a unified theory that accounts for the shape of the retention function and other memory phenomena. Deciding on whether or not it is reasonable to assume one retention function for a wide range of conditions and deciding on an adequate mathematical description of that retention function are the first two steps in this process.

\section{An Evaluation of the Four Best Fitting Functions}

One problem of describing data without guidance from a strong theory is interpreting that data. We have argued for four functions as descriptions of retention. How can we choose among these four, assuming their fits do not distinguish among them and that we do not want to wait for a comprehensive theory of memory? If one prefers (a) a simple two-parameter function, that (b) fits the data well, with (c) a verbal description that is consistent with a host of other data besides retention, that can be (d) quickly described to students, and (e) quickly computed on a hand calculator, the logarithmic function is best. However, colleagues in physics and mathematics will not agree. The first properties they consider are the boundary conditions, and at both $t=0$ and $t=$ infinity the logarithm is not well behaved. In addition, it cannot easily be derived from a mechanism as opposed to a principle.

The power function has the same advantages and disadvantages as the logarithmic function. It provides a somewhat poorer fit than the logarithmic function except for the savings and the autobiographical memory data sets. Its empirical disadvantage, however, may disappear if the range of the dependent measure of retention is large. It has the advantage of being consistent with an integrated attempt to understand human memory (Anderson, 1990, 1995; Anderson \& Schooler, 1991), but within this attempt the power function is only favored because it appears to fit change in the environment, and other functions might do this as well.

The exponential-power function does not have all the advantages of the logarithmic or power functions, but it has none of their disadvantages. The exponential power is well behaved at the boundary conditions. It can be derived from mechanisms; we offered four to choose from, and there are more to be found in the literature. Moreover, it makes sense on an intuitive level in that it is like the exponential, long favored by psychologists, but is just different enough to fit the data. It routinely turns up in disparate fields that try to fit distributions (Indow, 1993), which should be a comfort to some and a worry to others. The hyperbolic-power function has the boundary condition and intuitive-sense advantages of the exponential-power function, but it lacks a derivation from a mechanism or a verbal explanation. Thus it has the advantage of providing a challenge to those inclined to find such derivations.

Our hope is that in considering retention functions in particular and memory in general the data sets assembled here serve as one basis for debate. They represent the empirical effort of those who have considered the problem of retention over the last century. Recently, debate about retention has occurred without much reference to data. The 210 data sets assembled here could change that. Each has advantages for some questions. Each is described fully in a published article or technical report. The data to make methodological and theoretical improvements on this attempt to understand retention exist in the assembled data sets. If criticisms or corrections are to be made, it would be 
both efficient and rhetorically elegant to use the data we have assembled to make them.

\section{Conclusion}

Psychologists once formulated laws to account for regularities in behavior, such as Fechner's law, Herrnstein's matching law, Jost's laws, Stevens' law, and Weber's law. Such lawmaking has gone out of style in cognitive psychology. Perhaps the term law seems pretentious for the act of documenting quantifiable empirical regularities of broad application and sometimes initially weak theoretical underpinnings. But laws have uses besides providing instructors with easy-to-write short-answer questions. They formalize the regularities that students of the field should know in a way that theories can use. We have established a law: the logarithmic-loss law. Given our current state of knowledge, we must offer it in three alternative mathematical formulations: the power law, the hyperbola-in-the-square-rootof- $t$ forgetting function, and the Rubin-Wenzel-WickelgrenWeibull-Williams-Watts exponential-power law. Our law in any of its mathematical forms summarizes what we now know about the quantitative course of forgetting. It will serve its purpose either if it remains a fact of nature or if it suggests advances that rapidly render it obsolete.

\section{References}

Alescio-Lautier, B., \& Soumireu-Mourat, B. (1986). Comparison of retention and extinction of a visual discrimination as an index of forgetting in mice. Animal Learning and Behavior, 14, 197-204.

Ammons, R. B., Farr, R. G., Bloch, E., Neumann, E., Dey, M., Marion, R., \& Ammons, C. H. (1958). Long term retention of perceptual motor skills. Journal of Experimental Psychology, 55, 318-328.

Anderson, J. R. (1990). The adaptive character of thonght. Hillsdale, NJ: Erlbaum

Anderson, J. R. (1995). Learning and memory: An integrated ap proach. New York: Wiley.

Anderson, J. R., \& Schooler, L. J. (1991). Reflections of the environment in memory. Psychological Science, 2, 396-408.

Baddeley, A. D. (1986). Working memory. Oxford, England: Oxford University Press.

Baddeley, A. D. (1990). Human memory: Theory and practice. Boston: Allyn and Bacon.

Bahrick, H. P. (1965). The ebb of retention. Psychological Review: 72 , 60-73.

Bahrick, H. P. (1983). The cognitive map of a city: Fifty years of learning and memory. In G. H. Bower (Ed.), The psychology of learning and motivation (Vol. 17, pp. 125-163). New York: Academic Press.

Bahrick, H. P. (1984). Semantic memory content in permastore: Fifty years of memory for Spanish learned in school. Journal of Experimental Psychology: General, 113, 1-27.

Bahrick, H. P., Bahrick, P. O., \& Wittlinger, R. P. (1975). Fifty years of memory for names and faces: A cross-sectional approach. Journal of Experimental Psychology: General, 104, 54-75.

Ballard, P. B. (1913). Obliviscence and reminiscence. British Journal of Psychology Monographs Supplement, 3-82.

Banks, R. B. (1994). Growth and diffusion phenomena: Mathematical frameworks and applications. Berlin: Springer-Verlag.

Baron, A., \& Cerella, J. ( I 993), Laboratory tests of the disuse account of cognitive deficits. In J. Cerella, J. Rybash, W. Hoyer, \& M. L. Commons (Eds.), Adult information processing: Limits on loss (pp. 175 203). San Dicgo: Academic Press.
Bean, C. H. ( 1912). The curve of forgetting. Archives of Psychology, 2. $1-47$.

Begg, I., \& Wickelgren, W. A. (1974). Retention functions for syntactic and lexical vs. semantic information in sentence recognition memory. Memory and Cognition, 2, 353-359.

Bendler, J. T., \& Shlesinger, M. F. (1987). Defect-diffusion models of relaxation. Journal of Molecular Liquids, 36, 37-46.

Bjork, R. A., \& Whitten, W. B. ( 1974 ). Recency-sensitive retrieval processes in long-term free recall. Cognitive Psychology, 6, 173-189.

Bogartz, R. S. (1990a). Evaluating forgetting curves psychologically. Journal of Experimental Psychology: Learning, Memory, and Cognition, 16, 138-148.

Bogartz, R. S. (1990b). Learning-forgetting rate independence defined by forgetting function parameters or forgetting function form: Reply to Loftus and Bamber and to Wixted. Journal of Experimental Psychology: Learning. Memory, and Cognition, 16, 936-945.

Boreas, T. (1930). Experimental studies of memory: Second preliminary communication. The rate of forgetting. Praktika Acad Athenes, $5,382-396$.

Brainerd, C. J., Reyna, V. F., Howe, M. L., \& Kingma, J. ( 1990). The development of forgetting and reminiscence. Monographs of the Society for Research in Child Development, 55 (3-4, Serial No. 222), 192.

Bregman, A. S. (1968). Forgetting curves with semantic, phonetic, graphic, and contiguity cues. Journal of Experimental Psychology, 78, 539-546.

Burtt, H. E., \& Dobell, E. M. (1925). The curve of forgetting for advertising material. Journal of Applied Psychology, 9, 5-21.

Conway, M. A., Cohen, G., \& Stanhope, N. (1991). On the very long term retention of knowledge acquired through formal education: Twelve years of cognitive psychology. Journal of Experimental Psychology: General, 120, 395-409.

Conway, M. A., \& Rubin, D. C. (1993). The structure of autobiographical memory. In A. E. Collins, S. E. Gathercole, M. A. Conway, \& P. E. Morris (Eds.), Theories of memory (pp. 103-137). Hove, Sussex, England: Erlbaum.

Cox, D. R. ( 1962). Renewal theory. London: Methuen

Crovitz, H. F., \& Schiffiman, H. (1974). Frequency of episodic memories as a function of their age. Bulletin of the Psychonomic Society. 4. 517-518.

Denny, M. R., Clos, C., \& Rilling, M. (1989). Delayed matching to sample in rats in a y-maze: Instances of facilitation and immediate cross-modal transfer. Bulletin of the Psychonomic Society, 27, 141144.

Ebbinghaus, H. (1964). Memory: A contribution to experimental psychology (H. A. Ruger \& C. E. Bussenius, Trans.). New York: Dover. (Original work published 1885)

Estes, W. K. (1956). The problem of inference from curves based on group data. Psychological Bulletin, 53, 134-140.

Fajnsztejn-Pollack, G. ( 1973). A developmental study of the decay rate in long term memory. Journal of Experimental Child Psychology. 16. 225-235.

Finkenbinder, E. D. (1913). The curve of forgetting. American Journal of Psychology. 24, 8-32.

Fioravanti, M., \& Di Cesare, F. (1992). Forgetting curves in long term memory: Evidence for a multistage model of retention. Brain and Cognition, 18, 116-124.

Gehring, R. E., Toglia, M. P., \& Kimble, G. A. (1976). Recognition memory for words and pictures at short and long retention intervals. Memory and Cognition, 4, 256-260.

Giambra, L. M., \& Arenberg, D. (1993). Adult aging in forgetting sentences. Psychology and Aging, 8, 451-462.

Gillund, G., \& Shiffrin, R. M. ( 1984). A retrieval model for both recall and recognition. Psychological Review, 91, 1-67. 
Glasnapp, D. R., Poggio, J. P., \& Ory, J. C. ( 1978). End-of-course and long term retention outcomes for mastery and nonmastery learning paradigms. Psychology in the Schools, 15, 595-603.

Glenberg, A. M., \& Swanson, N. G. (1986). A temporal distinctiveness theory of recency and modality effects. Journal of Experimental Psychology: Learning, Memory, and Cognition, 12, 3-15.

Green, D. M., \& Swets, J. A. (1966). Signal detection theory and psychophysics. New York: Wiley.

Greenwald, A. G. (1975). Consequences of prejudice against the null hypothesis. Psychological Bulletin, 82, 1-20.

Gumbel, E. J. (1958). Statistics of extremes. New York: Columbia University Press.

Guttentag, R. E. (1990). Issues in the study of age differences in forgetting. Monographs of the Society for Research in Child Development, 55(3-4, Serial No. 222), 94-99.

Harnett, P., McCarthy, D., \& Davison, M. (1984). Delayed signal detection, differential reinforcement, and short term memory in the pigeon. Journal of the Experimental Analysis of Behavior, 42, 87-111.

Hellyer, S. (1962). Frequency of stimulus presentation and short-term decrement in recall. Journal of Experimental Psychology, 64, 650.

Helson, H. (1964). Adaptation-level theory: An experimental and systematic approach to behavior. New York: Harper \& Row.

Hintzman, D. L. (1986). "Schema abstraction" in a multiple-trace memory model. Psychological Review, 93, 411-428.

Hulicka, I. M., \& Weiss, R. L. (1965). Age differences in retention as a function of learning. Journal of Consulting Psychology, 29, 125-129.

Indow, T. (1993). Retention curves of artificial and natural memory: Tight and soft models (Institute for Mathematical Behavioral Sciences, Technical Report Series, MBS 93-11). Irvine: University of California.

Jans, J. E., \& Catania, C. (1980). Short-term remembering of discriminative stimuli in pigeons. Journal of the Experimental Analysis of Behavior, 34, 177-183.

Jarrard, L. E., \& Moise, S. L. ( 1970). Short term memory in the stumptail macaque: Effect of restraint of behavior on performance. Learning and Motivation, 1, 267-275.

Johnson, G. J. (1991). A distinctiveness model of serial learning. Psychological Review; 98, 204-217.

Kausler, D. H. (1974). Psychology of verbal learning and memory. New York: Academic Press.

Kausler, D. H. (1982). Experimental Psychology and Human Aging. New York: Wiley.

King, H. E. (1963a). The retention of sensory experience: I. Intensity. Journal of Psychology, 56, 283-290.

King, H. E. (1963b). The retention of sensory experience: II. Frequency. Journal of Psychology, 56, 291-298.

Krueger, W. C. F. (1929). The effect of overlearning on retention. Journal of Experimental Psychology, 12, 71-78.

Laming, D. (1992). Analysis of short-term retention: Models for Brown-Peterson experiments. Journal of Experimental Psychology: Learning, Memory, and Cognition, 18, 1342-1365.

Lavach, J. F. (1971). The effects of emotional arousal on short vs. long term retention of continuously presented information. Final report. Williamsburg, VA: College of William and Mary.

Linton, M. (1975). Memory for real world events. In D. A. Norman \& D. E. Rumelhart (Eds.), Explorations in cognition (pp. 376-404), San Francisco: Freeman.

Loftus, G. R. (1985a). Consistency and confoundings: Reply to Slamecka. Journal of Experimental Psychology: Learning, Memory, and Cognition, 11, 817-820.

Loftus, G. R. (1985b). Evaluating forgetting curves. Journal of Experimental Psychology: Learning, Memory, and Cognition, 11, 397-409.

Loftus, G. R. (1993). Editorial comment. Memory \& Cognition, 21,1 3.
Loftus, G. R., \& Bamber, D. (1990). Learning-forgetting independence, unidimensional memory models, and feature models: Comment on Bogartz. Journal of Experimental Psychology: Learning, Memory, and Cognition. 16, 916-926.

Longmore, B. E., \& Knight, R. G. (1988). The effect of intellectual deterioration on retention deficits in amnesic alcoholics. Journal of Abnormal Psychology, 97, 448-454.

Luh, C. W. (1922). The conditions of retention. Psychological Monographs, 31 , whole no. 142 .

MacLeod, C. M. (1988). Forgotten but not gone: Savings for pictures and words in long term memory. Journal of Experimental Psychology: Learning, Memory, and Cognition, 14, 195-212.

Mazur, J., \& Hastie, R. (1978). Learning as accumulation: A reexamination of the learning curve. Psychological Bulletin, 85, 1256-1274.

McGeogh, J. A. (1932). Forgetting and the law of disuse. Psychological Review, 39, 352-370.

Meehl, P. E. (1978). Theoretical risks and tabular asterisks: Sir Karl, Sir Ronald, and the slow progress of soft psychology. Journal of Consulting and Clinical Psychology, 46, 806-834.

Moise, S. J. (1970). Short term retention in macaca speciosa following interpolated activity during matching from sample. Journal of Comparative and Physiological Psychology, 73, 506-514.

Morrison, F. J., Haith, M. M., \& Kagan, J. ( 1980). Age trends in recognition memory for pictures: The effects of delay and testing procedure. Bulletin of the Psychonomic Society, 16, 480-483.

Murdock, B. B., Jr. (1960). The distinctiveness of stimuli. Psychological Review, 67, 16-31.

Murdock, B. B., Jr. (1961). The retention of individual items. Journal of Experimental Psychology, 62, 618-625.

Murdock, B. B., Jr. (1982). A theory for the storage and retrieval of of item associative information. Psychological Review, 89, 609-627.

Nelson, K. R., \& Wasserman, E. A. (1978). Temporal factors influencing the pigeon's successful matching to sample performance: Sample duration, intertrial interval, and retention interval. Journal of the Experimental Analysis of Behavior, 30, 153-162.

Nelson, T. O., Shimamura, A. P., \& Leonescio, J. (1980). Large effects on long term retention after standard list learning and adjusted learn. ing. Behavior Research Methods and Instrumentation, 12, 42-44.

Nelson, T. O., \& Vining, S. K. (1978). Effects of semantic versus structural processing on long-term retention. Journal of Experimental Psychology: Iluman Learning and Memory, 4, 198-209.

Newell, A., \& Rosenbloom, P. S. (1981). Mechanisms of skill acquisition and the law of practice. In J. R. Anderson (Ed.), Cognitive skills and their acquisition (pp. 1-55). Hillsdale, $\mathrm{NJ}$ : Erlbaum.

Palmer, R. G., \& Stein, D. L. (1989a). Glasses: I. Phenomenology. In D. L. Stein (Ed.), Lectures in the sciences of complexity: Lectures (Vol. 1, 759-769). Redwood, CA: Addison-Wesley.

Palmer, R. G., \& Stein, D. L. (1989b). Glasses: II. Models of glassy relaxation. In D. L. Stein (Ed.), Lectures in the sciences of complexity (pp. 771-785). Redwood City, CA: Addison-Wesley

Peterson, L. R., \& Peterson, M. J. ( 1959). Short term retention of individual verbal items. Journal of Experimental Psychology, 58, 193198.

Radosavljevich, P. R. (1907). Das Behalten und Vergessen bei Kindern und Erwachsenen nach experimentellen Untersuchungen [An experimental investigation of the retention and forgetting of children and adults]. Leipzig: Nemnich.

Ratcliff, R. (1990). Connectionist models of recognition memory: Constraints imposed by learning and forgetting functions. Psychological Review; 97, 285-308.

Roberts, W. A., \& Grant, D. S. (1978). An analysis of light-induced retroactive inhibition in pigeon short-term memory. Journal of EXperimental Psychology: Animal Behavior Processes, 4, 219-236.

Roediger, H. L., III, \& McDermott, K. B. (1993). Implicit memory in 
normal human subjects. In F. Boller \& J. Grafman (Eds.), Handbook of neuropsychology (Vol. 8, pp. 63-131). Amsterdam: Elsevier.

Roediger, H. L., III, \& Payne, D. G. (1982). Hypermnesia: The role of repeated testing. Journal of Experimental Psychology: Learning. Memory, and Cognition, 8, 66-72.

Rovee-Collier, C. (1993). The capacity for long-term memory in infancy. Current Directions in Psychological Science, 2, 130-135.

Rubin, D. C. (1982). On the retention function for autobiographical memory. Journal of Verbal Learning and Verbal Behavior, 21, 21-38.

Rubin, D. C. (1985). Memorability as a measure of processing: A unit analysis of prose and list learning. Journal of Experimental Psychologv: General, 114, 213-238.

Rubin, D. C. (1989). Issues of regularity and control: Confessions of a regularity freak. In L. W. Poon, D. C. Rubin, \& B. A. Wilson (Eds.), Everyday cognition in adult and later life (pp. 84-103). Cambridge. England: Cambridge University Press.

Rubin, D. C. (1995). Memory in oral traditions: The cognitive psychology of epic, ballads, and counting-out rhymes. New York: Oxford University Press.

Rubin, D. C., \& Baddeley, A. D. (1989). Telescoping is not time compression: A model of dating autobiographical events. Memory and Cognition. 17, 653-661.

Rubin, D. C., \& Wallace, W. T. (1989). Rhyme and reason: Analyses of dual cues. Journal of Experimental Psychology: Learning, Memory, and Cognition, 15, 698-709.

Rubin, D. C., Wetzler, S. E., \& Nebes, R. D. (1986). Autobiographical memory across the adult lifespan. In D. C. Rubin (Ed.), Autobiographical memory (pp. 202-221). Cambridge, England: Cambridge University Press.

Runquist, W. (1983). Some effects of remembering on forgetting. Memory and Cognition, 11, 641-650.

Serra, M., \& Nairne, J. S. (1993). Design controversies and the generation effect: Support for an item-order hypothesis. Memory \& Cognition, 2l, 34-40.

Shimp, C. P.. \& Moffitt, M. (1977). Short term memory in the pigeon: Delayed pair comparison procedures and some results. Journal of the Experimental Analysis of Behavior, 28, 15-25.

Simon, H. A. (1966). A note on Jost's law and exponential forgetting. Psychometrika, 31, 505-506.

Slamecka, N. J. (1985). On comparing rates of forgetting: Comment on Loftus. Journal of Experimental Psychology: Learning, Memory, and Cognition, 11, 812-816.

Slamecka, N. J., \& McElree, B. (1983). Normal forgetting of verbal lists as a function of their degree of learning. Journal of Experimental Psychology: Learning, Memory, and Cognition, 9, 384-397.

Sloman, S. A., Hayman, C. A. G., Ohta, N., Law, J., \& Tulving, E. (1988). Forgetting in primed fragment completion. Journal of Experimental Psychology: Learning, Mernory, and Cognition, 14, 223239.

Spitzer, H. F. (1939). Studies in retention. Journal of Educational Psychology, 30, 641-656.

Squire, L. R. (1989). On the course of forgetting in very long term memory. Journal of Experimental Psychology: Learning. Memory, and Cognition, 15, 241-245.

Staats, A. W., Minke, K. A., \& Stalling, R. B. (1970). Long term retention of conditioned attitudes (Report No. TR-6). Honolulu: Hawaii University, Department of Psychology. (ERIC Document Reproduction Service No. ED 043215 )

Staddon, J. E. R. (1983). Adaptive behavior and learning. Cambridge, Lngland: Cambridge University Press.

Staddon, J. E. R. ( 1993). On rate-sensitive habituation. Adaptive Behavior, 1, 421-436.
Stevens S. S. (1975). Psychophysics: Introduction to its perceptual, neural, and social prospects. New York: Wiley.

Strong, E. K. (1913). The effect of time interval upon recognition memory. Psychological Review, 30, 339-372.

TableCurve 2D [Computer software]. (1994). San Rafael, CA: Jandel Scientific.

Thompson, C. P. (1982). Memory for unique personal events: The roommate study. Memory and Cognition, 10, 324-332.

Tsai, C. (1924). A comparative study of retention curves for motor habits. Comparative Psychology Monographs, 2, 1-29.

Turvey, M. T., Brick, P., \& Osborn, J. (1970). Proactive interference in short-term memory as a function of prior-item retention interval. Quarterly Journal of Experimental Psychology, 22, 142-147.

Turvey, M. T., \& Weeks, R. A. (1975). Effects of proactive interference and rehearsal on the primary and secondary components of short term retention. Quarterly Journal of Experimental Psychology, 27, $47-62$.

Underwood, B. J. (1966). Experimental psychology (2nd ed.). New York: Appleton-Century-Crofts.

Waugh, N. C., \& Norman, D. A. (1965). Primary memory. Psychological Review, 72, 89-104.

Weibull, W. (1951). A statistical distribution function of wide applicability. Journal of Applied Mechanics, 18, 293-297.

Wheeler, M. A., \& Roediger, H. L., III. ( 1992). Disparate effects of repeated testing: Reconciling Ballard's (1913) and Bartlett's (1932) results. Psychological Science, 3, 240-245.

White, G. K. (1985). Characteristics of forgetting functions in delayed matching to sample. Journal of the Experimental Analysis of Behavior, 44, 15-34.

White, G. K., \& McKenzie, J. (1982). Delayed stimulus control: Recall for single and relational stimuli. Journal of the Experimental Analysis of Behavior, 38, 305-312.

Wickelgren, W. A. (1968). Sparing of short term memory in an amnesic patient: Implications of strength theory of memory. Neuropsychologia, 6. 235-244.

Wickelgren, W. A. (1972). Trace resistance and the decay of long-term memory. Journal of Mathematical Psychology, 9, 418-455.

Wickelgren, W. A. (1973). The long and the short of memory. Psychological Bulletin, 80, 425-38.

Wickelgren, W. A. ( 1974a). Single-trace fragility theory of memory dynamics. Memory \& Cognition, 2, 775-780.

Wickelgren, W. A. (1974b). Strength/resistance theory of the dynamics of memory storage. In D. H. Krantz, R. C. Atkinson, R. D. Luce, \& P. Suppes (Eds.), Contemporary developments in mathematical psychology: Learning, memory and thinking (pp. 209-242). San Francisco: Freeman.

Wickelgren, W. A. (1975a). Age and storage dynamics in continuous recognition memory. Developmental Psychology, II, 165-169.

Wickelgren, W. A. (1975b). Alcoholic intoxication and memory storage dynamics. Memory \& Cognition, 3, 385-389.

Wilson, B., \& Boakes, R. A. (1985). A comparison of the short term memory performances of pigeons and jackdaws. Animal Learning and Behavior, 13, 285-290.

Wixted, J. T. (1990). Analyzing the empirical course of forgetting. Journal of Experimental Psychology: Learning, Memory, and Cognition, 16, 927-935.

Wixted, J. T., \& Ebbesen, E. B. (1991). On the form of forgetting. Psychological Science, 2, 409-415.

Woodworth, R. S. (1938). Experimental psychology. New York: Henry Holt.

Received January 20, 1995

Revision received March 5, 1996 Accepted April 3, 1996 